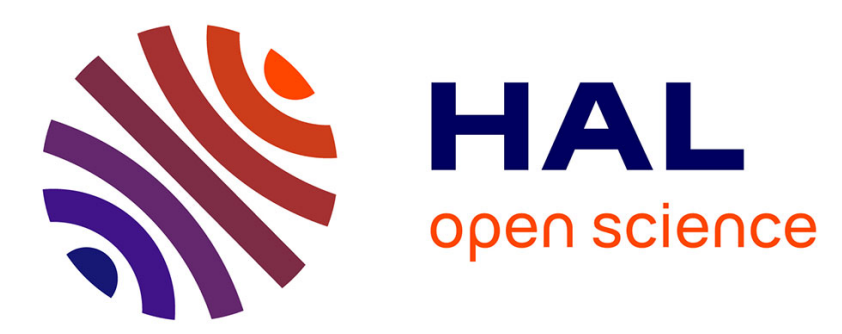

\title{
Mãos na argila: notas para uma abordagem da materialidade da escrita cuneiforme
}

\author{
Leandro Penna Ranieri, Anita Fattori
}

\section{To cite this version:}

Leandro Penna Ranieri, Anita Fattori. Mãos na argila: notas para uma abordagem da materialidade da escrita cuneiforme. Anais do Museu Paulista, 2021, ANAIS DO MUSEU PAULISTA, 29, 10.1590/1982-02672021v29e58 . hal-03457224

\section{HAL Id: hal-03457224 \\ https://hal.science/hal-03457224}

Submitted on 30 Nov 2021

HAL is a multi-disciplinary open access archive for the deposit and dissemination of scientific research documents, whether they are published or not. The documents may come from teaching and research institutions in France or abroad, or from public or private research centers.
L'archive ouverte pluridisciplinaire HAL, est destinée au dépôt et à la diffusion de documents scientifiques de niveau recherche, publiés ou non, émanant des établissements d'enseignement et de recherche français ou étrangers, des laboratoires publics ou privés. 


\title{
Mãos na argila: notas para uma abordagem da materialidade da escrita cuneiforme ${ }^{1}$
}

Hands on clay: notes for an approach to the materiality of cuneiform writing

hitps://doi.org/10.1590/1982-02672021v29e58

\section{LEANDRO PENNA RANIERI²}

hitps://orcid.org/0000-0002-3709-1 394

Universidade de São Paulo / São Paulo, SP, Brasil

\author{
ANITA FATTORI ${ }^{3}$ \\ hitps://orcid.org/0000-000 1-6998-7366 \\ Universidade de São Paulo / São Paulo, SP, Brasil
}

RESUMO: Este artigo objetiva compreender a relação entre a materialidade da escrita e a escrita cuneiforme na antiga Mesopotâmia. Inicialmente, discutimos como as abordagens tradicionais aplicadas a textos, a partir do "modelo linguístico" e suas derivações, contribuíram para a desmaterialização da escrita ao priorizar a mensagem escrita em detrimento do material inscrito. Em seguida, debatemos os conceitos de material e materialidade, levando em conta tanto as condições de existência e as propriedades materiais do suporte/objeto, como as relações materiais que fazem com que a escrita se concretize. Por fim, apresentamos dois estudos de caso que consideram a relação entre sujeitos, objetos e ambientes dentro do contexto em que circulam, partindo de abordagens analíticas mais recentes, aplicadas aos estudos de cultura material, que conferem à materialidade um papel ativo nas relações sociais. $\bigcirc$ primeiro estudo de caso apresenta os tabletes de argila em um contexto preciso de relações administrativas, problematizando a visão de que seriam suportes ou veículos para uma mensagem. Já no segundo, trazemos as possíveis compreensões da relação entre materialidade, texto e imagem em relevos parietais palacianos.

\begin{abstract}
1. Agradecemos a Rafael dos Santos Pires, Thais Rocha da Silva e Renan Falcheti Peixoto pela leitura crítica do manuscrito. A Pedro Paulo Melara pelo auxílio na adaptação das figuras. Ao professor doutor Marcelo Rede pela leitura crítica e por ter compartilhado conosco seu manuscrito em preparação. Aos pareceristas da Revista Anais do Museu Paulista pelos comentários úteis ao refinamento final do artigo, bem como à assistência editorial pelo processo de preparação e revisão para publicação.

2. Doutor em ciências pelo Programa de História Social da Faculdade de Filosofia, Letras e Ciências Humanas (FFLCH) da Universidade de São Paulo (USP). É pesquisador (pós-doutorado) junto à FFLCH-USP e ao Laboratório do Antigo Oriente Próximo (Laop-USP), com bolsa da Fundação de Amparo à Pesquisa do Estado de São Paulo (Fapesp, processo $\mathrm{n}^{\circ}$ 2018/13540-7). E-mail: <ranierileandro@usp.br>.
\end{abstract}

3. Mestre em filosofia pelo Programa de Estudos Culturais da Escola de Artes, Ciên- 
cias e Humanidades (EACH) da Universidade de São Paulo (USP). É doutoranda do Programa de História Social da Faculdade de Filosofia, Letras e Ciências Humanas (FFLCH-USP) e da École Doctorale d'Histoire da Université Paris 1 Panthéon-Sorbonne, com bolsa da Fundação de Amparo à Pesquisa do Estado de São Paulo (Fapesp, processo $\mathrm{n}^{\circ}$ 2019/12945-6 e 2020/073954). É membro do Laboratório do Antigo Oriente Próximo (Laop-USP). E-mail: <anitafattori2@gmail.com>.
PALAVRAS-CHAVE: Materialidade da escrita. Cuneiforme. Mesopotâmia.

ABSTRACT: This paper focuses on the relationship between the materiality of writing and the cuneiform writing system in ancient Mesopotamia. To this end, it will first look at the traditional approaches to the analyses of texts, from the "linguistic model" and its derivatives, and how they contributed to the dematerialization of writing by prioritizing the written message over the written material. Then, it will discuss the concepts of material and materiality, considering the conditions for existence and material properties of inscribed objects, as well as the material relations that enable the act of writing. Finally, from more recent analytical approaches in material culture studies that assign a more active role to materiality in structuring social relations, this study examines the relationship between subjects, objects, and the environments in which they are inserted through two case studies. The first one looks at clay tablets in administrative relations, problematizing the understanding of tablets as supports or vehicles for messages. The second case study explores alternatives for conceptualizing the dynamic relationship among materiality, text, and image in palace wall reliefs.

KEYWORDS: Materiality of writing, Cuneiform, Mesopotamia. 
A abundância dos textos cuneiformes se justifica em vista da escrita em diferentes suportes - dos menos conhecidos devido a sua fragilidade, como o papiro e a cera sobre pranchas de madeira, até pedras mais rígidas e metais - e de um número elevado de pessoas especializadas nesse tipo de escrita, os escribas, que eram distribuídos em diferentes funções e estavam coligados muitas vezes a uma tradição familiar. Sabendo da importância do corpus da cultura cuneiforme para os estudos da antiguidade próximo-oriental, em termos quantitativos a maior fonte para o estudo da Mesopotâmia são os tabletes feitos de argila, sobre os quais eram impressos os sinais cuneiformes. ${ }^{4}$ Esse tipo de escrita nesse suporte foi transmitido quase diretamente de seu contexto final na antiguidade até a contemporaneidade. ${ }^{5}$

Todavia, na assiriologia, campo que lida com os estudos da Mesopotâmia, as discussões sobre a importância da articulação entre materialidade e escrita cuneiforme tiveram uma integração tardia e, no limite, restritiva. Balke e Tsouparopoulou afirmam que, para o tratamento da epigrafia, a prática hermenêutica da filologia do Antigo Oriente Próximo prevaleceu por mais de cem anos, ${ }^{\circ}$ ou seja, abordagens orientadas pelo texto e pela textualidade são inerentes à formação do campo assiriológico, além de fazerem parte do quadro mais amplo da formação da história antiga.

Baseadas sobretudo nas teorias da prática social de Pierre Bourdieu e Anthony Giddens, 7 bem como de Alfred Gell8 sobre as agências materiais e humanas e de Bruno Latour ${ }^{9}$ sobre a interrelação em rede entre sujeitos e objetos, as pesquisas abordaram as relações entre mundo social e mundo material ao repensar o papel passivo atribuído à materialidade, 10 buscando enfatizar sua importância para a construção do conhecimento, da cognição e das interações humanas. Surgidas a partir da década de 1980 e integradas no campo da assiriologia, sobretudo nos anos 2000, ${ }^{11}$ essas diversas tendências procuraram redefinir as fronteiras entre o mundo das pessoas e o mundo das coisas e reconhecer a materialidade como componente ativo das relações sociais. Como afirma Marcelo Rede, "[...] as diversas correntes abrigadas sob o rótulo de 'material turn' [...] conferiram à materialidade um estatuto socialmente ativo antes reservado aos seres animados". ${ }^{12}$

objetivo deste artigo é abordar a dimensão material da escrita cuneiforme nos tabletes de argila e suas principais implicações sociais ao longo de sua história, apresentando e debatendo a materialidade da escrita e retomando os usos dos tabletes cuneiformes enquanto artefatos inscritos. Consideramos que o texto é mais do que sua dimensão escrita e que os tabletes não são apenas seu suporte ou
4. Estima-se, numa perspectiva mais cautelosa, que cerca de meio milhão de tabletes foram escavados das centenas de sítios arqueológicos dos territórios do Iraque e da Síria (CHARPIN, 2008, p. 257). A partir deles, entendemos que o uso do sistema de escrita cuneiforme estendeu-se de aproximadamente 3200 AEC a 75 EC e que as principais línguas da região a fazerem uso desse sistema foram o sumério e o acadiano em todas as suas variantes. Aqui, consideramos que a escrita cuneiforme, tanto como processo (a produção do texto) quanto como resultado (o texto pronto), constituiu uma prática cultural cuja continuidade se estendeu por mais de $3 \mathrm{mil}$ anos de história.

5. Matthews (2013, p. 72) e Von Dassow (2018, p. 821-822).

6. Balke e Tsouparopoulou (2016, p. 9).

7. Bourdieu (1984) e Giddens (1994).

8. Gell (1998).

9. Latour (1999, 2005).

10. Hicks (2010, p. 45) e Rede (2012, p. 140).

11. Especificamente sobre a materialidade da escrita, citamos, como exemplo, o volume organizado por Delnero e Lauinger (2015). A abordagem proposta por eles busca compreender "como diferentes tipos de textos cuneiformes moveram-se e funcionaram como objetos no espaço social" (p. 2). Tal transmissão também conta com a vantagem caraterística da própria argila, que, quando seca, tem aumentada a sua resistência.

12. Marcelo Rede. A materialidade e divino na antiga Mesopotâmia: questões 
teóricas e possibilidades analíticas. Manuscrito.

13. Durante a redação final deste artigo, encontramos a publicação do dossiê "Dimensões materiais da cultura escrita" (Anais do Museu Paulista, v. 28, 2020). O tema e as preocupações teórico-metodológicas da coletânea e de nosso artigo são semelhantes. Contudo, a natureza das fontes e a bibliografia de base não poderia ser mais heterogênea. $\mathrm{O}$ contraste entre os textos parece-nos salutar e destacamos a introdução de Almada (2020)

14. Vanstiphout (1995, p. 2181-2182). veículo para uma mensagem. A dimensão material envolve, portanto, a materialização da escrita na argila, a mobilização de todas as ferramentas, cognitivas e materiais, necessárias para sua execução, bem como a permanência do objeto inscrito nas relações sociais mais ou menos próximas de sua produção. Buscaremos recolocar a materialidade em conjunto à abordagem filológica, histórica, arquivística, sociológica etc. dos tabletes de argila escritos em cuneiforme. Essa recolocação poderá servir de operação para diferentes tipos de pesquisa, como investigações históricas que mobilizem documentação cuneiforme. ${ }^{13}$

Nesse sentido, a proposta deste texto se organiza em três momentos, todos coligados por um interesse teórico-metodológico sobre como tratar os tabletes de argila com escrita cuneiforme para além dos textos neles escritos. Nosso ponto de partida é explicitar o modo pelo qual as abordagens tradicionais, especialmente o chamado "modelo linguístico", deram prioridade ao conteúdo dos textos em detrimento de seu aspecto material. Em seguida, a partir de preocupações dos pesquisadores em diferentes campos, especialmente a arqueologia, antropologia e história, propomos revisitar as definições de material e materialidade, além de considerar essas noções em contexto. Por fim, por meio de dois estudos de caso contrastantes, buscaremos reposicionar a materialidade da escrita cuneiforme.

\section{ESCRITA COMO VEÍCULO DE CONTEÚDO}

Na interface entre arqueologia e história observamos, de um lado, a supervalorização do conteúdo do texto e, de outro, o esquecimento do suporte material dos objetos, levando à desmaterialização da escrita. Nesse sentido, a retomada da materialidade da escrita realça não apenas o interesse pelo próprio material, pelo aspecto físico do objeto, como também reconsidera o modo de tratar os objetos inscritos em cada contexto.

Antes de apresentar a articulação entre memória e letramento no Antigo Oriente Próximo, Vanstiphouł ${ }^{14}$ ajuda a entender os elementos interrelacionados da escrita, não só a escrita cuneiforme, por meio de três aspectos principais: (1) o aspecto operacional de gravar os sinais em um suporte. No caso da escrita cuneiforme, o suporte mais comum que nos chegou foi a argila, que, úmida, possibilita a impressão de sinais por meio de um instrumento denominado genericamente de stylus. (2) $\bigcirc$ aspecto funcional de realizar a fixação de uma mensagem no tempo-espaço. Conforme o autor, esse aspecto implica a existência 
de um contato (entre pessoas) e de um código (linguagem e sistema de escrita). Então, a mensagem escrita se faz "[...] na ausência de um endereçado e algumas vezes do contexto" 15 sobre o qual se trata e/ou se produz a mensagem escrita. Por fim, (3) o aspecto material do objeto que resulta dessa operação, que, segundo o autor, não coincide com a mensagem em si.

Esses três elementos se correlacionam a uma noção de escrita sob a ótica do conteúdo produzido na forma de um texto (a mensagem), sem que se perca de vista outros aspectos, como a língua, o contato, a intenção, o contexto lausente ou presente). Contudo, nessa esquematização, qual é a condição do suporte material como elemento dessa interrelação? Paradoxalmente, o suporte é o que garante a existência da escrita, mas é subserviente à mensagem, que parece preceder o suporte e é o que deve ser comunicado. No caso da escrita cuneiforme, o tablete de argila recebe os sinais de uma mensagem a ser veiculada por ele.

Tal característica, inerente ao ato de escrever, fundamentou uma tradição que busca sentido apenas naquilo que está escrito, sentido, como alertam Delnero e Lauinger, que reflete uma noção de conteúdo como abstração, descolado de seu suporte material, mas, lembram os autores, a materialização da escrita ainda pertence a um contexto, também material, espacial e temporal, de relações sociais.

[...] examinar o conteúdo verbal de um texto sem considerar a multiplicidade de sentidos que eles podiam ter tido no contexto social no qual foram originalmente registrados, completados ou concebidos é justificável, particularmente quando um texto foi intencionado para ser lido por leitores em diferentes tempos e lugares. [...] No entanto, quando textos são delimitados a contextos espaciais e temporais específicos, o relacionamento entre o conteúdo de um texto e sua audiência é menos estável do que seria para textos que foram compostos para uma audiência ideal de leitores presentes e futuros que podiam esperar entender seu significado em qualquer lugar ou tempo. ${ }^{16}$

Partindo do argumento dos autores, a escrita e sua materialização transmitem ou veiculam um sentido a ser entendido por potenciais leitores, sejam eles pretendidos, ideais ou ocasionais, grupo do qual fazemos parte. No entanto, a pretensa estabilidade espaço-temporal do texto, após inscrito em seu suporte material, se contrasta com a inerente instabilidade do contexto social em que os textos se realizam, da concepção à sua função final. Ao circular, o significado de um texto não é estável, mas depende dos receptores. ${ }^{17}$

A abordagem tradicional dos textos, que fundamentou a vertente filológica dos estudos sobre a antiguidade, repercutiv em diferentes campos, especialmente na arqueologia. Os objetos encontrados com mais ou menos inscrições interessavam
15. Ibid., p. 2181.

16. Delnero e Lauinger (2015, p. 2). Compreendemos que os autores utilizam os termos "leitores/as" de forma genérica, sem comprometimento à validade de seu argumento, pois os autores têm conhecimento de que na antiguidade muitos textos eram "consumidos" oralmente, dado o baixo letramento das populações. Quando eram realmente lidos, isso implicava pessoas em posições sociais que permitiam algum nível de letramento.

17. Ibid. 
18. Uma crítica semelhante pode ser encontrada em relação à apropriação das fontes de cultura material pelos historiadores franceses que atuaram na revista Annales. Veja-se a tentativa de panorama teórico-metodológico de Pesez (1993). Em contraste, Rede (2012, esp. p. 142) reposiciona tanto a pretensa contribuição desse grupo, como as tendências interessadas na história e cultura material.

19. Piquette e Whitehouse (2013, p. 3). Tal proposição considera um modelo de interação entre escrita, materialidade, percepção e ambiente que inclui as noções de substância, superfície e meio, elaboradas por James Gibson, em The Ecological Approach to Visual Perception, de 1979. A teorização desse autor também fundamentou a produção do antropólogo Tim Ingold (1992, 2007, 2015).

20. Cardoso (2012, p. 226).

21. Rede (2012, p. 138).

22. Ibid., p. 140.

23. Hodder e Hutson (2003) e Boivin (2009). É emblemática a concepção de semiologia de Roland Barthes (1915-1980), que vai tentar compreender todo e qualquer sistema de representação (linguístico e figurativo) por meio de uma linguagem a ser decodificada dentro de seu próprio sistema de manifestação. A semiologia de Barthes fez avançar o modelo linguístico, proposto por Ferdinand de Saussure (1857-1913). Rede (2012) e Meneses (2012) reveem a posição desses contributos, em especial suas limitações para o tratamento, respectivamente, da cultura material e das fontes visuais.

24. Hodder (1989).

25. Rede (2012, p. 143). pelo conteúdo textual (a mensagem que portavam) e não por uma natureza particular em meio a outros objetos em um mesmo espaço de um sítio arqueológico. O resultado foi uma desmaterialização da escrita. ${ }^{18} \mathrm{Na}$ perspectiva de Piquette e Whitehouse, textualidade e arqueologia (entendida em sentido amplo, de campo dedicado à cultura material como objeto de estudo) são necessárias para formar uma visão não fragmentária entre escrita enquanto ato (a produção) e enquanto resultado (o consumo, importante para o entendimento do significado). O que interessa é "examinar o significado das marcas da escrita em relação às superfícies materiais nas quais elas ocorrem [...] e sua percepção multissensorial por humanos em diferentes condições ambientais". 19

A noção de suportes materiais como veículos também é herdeira da concepção de que cultura material é algo a ser lido, como um objeto que tem sua linguagem própria entendida por processo de decodificação. Essa concepção, tomada a partir do "modelo linguístico", se desenrolou ao longo do século XX na Europa e se desdobrou na linguística estrutural e na semiótica. Arqueologia e História agregaram ao seu arcabouço os recursos dessas proposições sobre os textos e a escrita. Cardoso lembra que a perspectiva linguística e semiótica favoreceu aos interesses dos historiadores, pois permite que "a noção de texto pode aplicar-se tanto a objetos verbais como não verbais", ${ }^{20}$ o que se somava às concepções de que os documentos, sempre considerados texto e, portanto, passíveis de leitura, constituíam as matérias-primas da História, implicando a fonte-documento como mero veículo para uma informação. Para Rede, a abordagem linguística revela o sentido desses conteúdos discursivos, independentemente do suporte, que seria a relação entre significado e significante. ${ }^{21} \bigcirc$ autor reconhece, ${ }^{22}$ assim como Hodder e Hutson e Boivin, que a linguística influenciou a arqueologia a partir da década de 1960 ao considerar que os objetos criam e comunicam sentidos/discursividade. ${ }^{23} \mathrm{O}$ ponto nodal da abordagem linguística é considerar que o signo (significante) linguístico, pictórico ou simbólico - tenha significado arbitrário. O problema é o nivelamento da natureza entre os tipos de signo (linguístico e material), como se ambos pudessem ser compreendidos do mesmo modo e recebessem sentido pelo mesmo processo. A partir disso, a matéria e a materialidade deixam de ser reconhecidas como elementos atribuidores de significado.

A partir desse modelo linguístico a cultura material é contraposta ao discurso linguístico pelo seu teor inconsciente, conforme lan Hodder, que também revisa o impacto desse modelo no campo da arqueologia até a década de 1980. Nesse caso, a distinção consciente-inconsciente e discurso-prática inclui a separação abstrato-concreto, sendo o primeiro mais importante que o segundo. ${ }^{24}$ Rede $^{25}$ afirma 
que a abordagem linguística apresenta, como consequência, desbalanços quanto ao tratamento entre os objetos e o que é abstrato (cultura, relações sociais etc.). $\bigcirc$ quadro epistemológico é tripartite: (1) há um desbalanço por um dualismo e por uma hierarquização entre imaterial (mais importante e superior) e material (inferior e menos importante); (2) a ênfase no discurso e na linguagem possui suas raízes idealistas (como lembra Rede, ${ }^{26}$ para o campo historiográfico, a zona de interesse é pelo material escrito, advinda da tradição da exegese bíblica e das tradições eruditas de leitura dos textos greco-latinos); (3) a interação do ser humano com o meio e seus objetos é um processo que começa no pensamento, transforma-se em ação de intervenção (mais ou menos determinada pelas estruturas sociais) até a materialização (produto da mente humana). ${ }^{27}$

A partir da década de 1980, a arqueologia seguiu outros caminhos, buscando o sentido dos objetos, por exemplo, tratando de possíveis aspectos psicológicos e cognitivos, gerando uma nova distinção entre o que era intencional, conceitual e, portanto, relativo à linguagem, e o que era material. ${ }^{28}$ Contudo, como afirma Rede, "ontologicamente, tal concepção [uma "semiologia de origem linguística", ou seja, o modelo linguístico] situava o processo de significação em uma sede cultural autônoma, desencarnada dos elementos (físicos, imagéticos) que vetorizavam os sentidos", ${ }^{29}$ o que fez com que se retomasse, de algum modo, a relação entre o significado (mentalizado, precedente) e o significante (material, posterior, secundário). Enfim, o resultado é a dificuldade tradicional em se analisar o significado de objetos de cultura material. ${ }^{30} \bigcirc$ significado dos objetos só poderia estar no pensamento e na subjetividade dos seres humanos, ideia que implicaria a dificuldade em retraçá-lo senão pela escrita. Interessado numa modalidade específica de cultura material (imagem) e na aplicabilidade como fonte de pesquisa historiográfica, Meneses constata sobre a associação entre ideia e expressão verbal: "se faz dos objetos mera duplicação de um discurso verbal ou verbalizável, desprezando a materialidade não verbal do meio empregado e, por outro lado, ignorando que tanto a ideia produz a forma, quanto é produzida por ela". ${ }^{31}$

Em comparação ao modo de abordar e tratar os textos, Hodder antecipou elementos sobre os significados materiais como ainda mais dependentes do mundo material. Em detrimento da concepção anterior que se baseava no sentido abstrato, os aspectos materiais são mais constritos ao ambiente material e social; sua "leitura" é diferenciada por não se configurarem por meio da linearidade, assim como apelam a diferentes aspectos da sensorialidade na sua relação com seres humanos. Tudo isso evita uma consideração de que a cultura material teria um significado prévio, arbitrário e sobreposto ao objeto. Ao contrário, seu significado é dado por seu uso num dado contexto. ${ }^{32}$
26. Ibid., p. 135.

27. Tal cadeia (pensamento, comportamento e matéria) interessa à mais recente arqueologia cognitiva, que muitas vezes tentou diminuir a distância entre os termos ou realçar suas articulações. Cf. nota 35 .

28. Hodder (1989, p. 254).

29. Rede (2012, p. 144-145).

30. Cf. Hodder (1989) e Rede (2012).

31. Meneses (2012, p. 251).

32. Hodder (1989) 
33. Boivin (2009). Desde então, as contribuições de Hodder avançaram em direção à proposição do emaranhamento de fios como modelo de interpretação e compreensão, situadas historicamente, do lugar dos sujeitos, objetos, instituições sociais e ambientes. Uma síntese dessa contribuição é bem pontuada numa entrevista com o próprio Hodder (Teixeira-Bastos; Ferreira; Hodder, 2020).

34. Hodder (1989, p. 262).

35. Essa perspectiva ganhou contornos teórico-metodológicos pela teoria do engajamento material, proposta por Renfrew (1982, 1994, 2004) e por Malafouris (2013).

36. Boivin (2009) e Rede (2012, p. 139).

37. Boivin (2009, p. 283).

38. Ingold (2007) e Knappett (2012).
Boivin considera a contribuição de Hodder emblemática da transição entre um modelo linguístico, aplicado à interpretação da cultura material, e uma revisão e consideração dos limites de tal abordagem. ${ }^{33}$ Sua perspectiva, uma abordagem contextual, ${ }^{34}$ recoloca os objetos em contexto que configura 0 sentido da materialidade, atrelando a perspectiva ao aspecto material da própria atividade e, portanto, da mente e do corpo dos seres humanos, outro elemento caro a abordagens recentes, como é o caso da arqueologia cognitiva. ${ }^{35}$ Contudo, Boivin e Rede reconhecem ${ }^{36}$ que tal avanço ainda mantinha presente um paralelo entre objetos/cultura material e textos/discursos, com a metáfora textual e a leitura semiótica/estruturalista ainda presentes. Em outras palavras, as pesquisas sobre o significado da cultura material continuaram "orientadas pela linguagem". ${ }^{37}$

Antes de avançar nas contribuições da discussão do tratamento das fontes de cultura material e materialidade dos objetos, é válido debater se a abordagem contextual serviria a uma "leitura" dos tabletes cuneiformes. $\bigcirc$ uso dado ao objeto em um contexto específico definiria ou garantiria seu sentido, estabelecido por meio do que chamaremos de relações materiais. Contudo, retomando a ideia de instabilidade de sentido de textos em seus contextos, questionamos: os tabletes também seriam instáveis, ou seja, eles ganhariam sentidos diversos em situações diversas de implementação, ou teriam um único sentido em seus processos sociais? Haveria diferentes sentidos, relativos à escrita e aos tabletes, que se diluiriam em ambientes de uso diferentes? As respostas dependem mais de elementos não textuais dos objetos inscritos (contexto, propriedades) e menos do texto em si, distinção válida entre o texto enquanto conteúdo/mensagem e o texło enquanto artefato. A análise de um objeto inscrito e a resposta a essas questões dependem de como se considera sua materialidade, que implica tanto as condições de existência e as propriedades materiais do suporte/objeto, como as relações materiais que fazem com que a escrita se concretize.

\section{ESCRITA E SUA MATERIALIDADE}

\section{O que é materialidade?}

As definições de matéria e materialidade nunca são óbvias; por exemplo, Ingold e Knappett reconhecem e chamam a atenção para a dificuldade em definir previamente os termos. ${ }^{38} \mathrm{~A}$ partir de sua revisão da literatura arqueológica e de 
estudos antropológicos e de cultura material, em Knappett encontramos uma abordagem interdisciplinar para a definição de materialidade. ${ }^{39} \bigcirc$ autor apresenta uma natureza relacional e multidimensional entre relações sociais e relações materiais, emergente da "conjunção ou intersecção do social e do material" ${ }^{40}$ Ingold, por sua vez, salienta a importância da matéria para essa discussão. No limite, discorre contra o conceito de materialidade se este for oposto ao material, isto é, "do que são feitas as coisas". ${ }^{41}$ Um dos problemas levantados pelo autor é que o mundo material definido pelos humanos acaba sendo um conjunto selecionado, pois nem todos os objetos, sejam "naturais" ou artificiais, fazem parte da contabilidade. Nas investigações e no senso comum, o que se costuma chamar de mundo material é um mundo de artefatos, restando os materiais naturais não transformados em objetos pelas culturas humanas, que compõem uma outra dimensão desse mundo material. Portanto, o que o autor questiona também é o que está englobado quando se fala em "material".

Ao buscar definir o que é materialidade e o que é material, a literatura pretende distinguir um elemento do outro, mesmo que isso sirva posteriormente para restabelecer uma relação entre ambos, seja de pertença, de precedência, ou de ordenação. Nessas tentativas, ao menos como os conceitos são descritos, o aspecto relacional/social tende a preceder lé o que define a materialidade em relação ao material) ou a suceder (é o que faz do material parte da vida social) a dimensão material. ${ }^{42}$ Vale notar que, em ambos os casos, a definição de materialidade já considera a teoria da ação social ${ }^{43}$ e a teoria da agência ${ }^{44}$ como contributos teóricos que, mesmo não declarados, são indispensáveis para qualquer começo de conversa.

Mesmo nos estudos de materialidade da escrita tenta-se de formas diversas circunscrever o conceito. Balke e Tsouparopoulou distinguem entre "materialidade da escrita (como um ato) e materialidade do texto (como artefato)". 45 Nesse caso, a materialidade da escrita implica também o ato da feitura do texto, este sendo um artefato, se considerado por sua presença material. Berti et al., por sua vez, delimitam a noção de materialidade como um conjunto de características de um artefato individual, o que engloba o material utilizado, a manufatura, sua dimensão, disposição visual e o design da escrita. ${ }^{46}$ Ou seja, os autores incluem as propriedades que têm nos aspectos físicos sua natureza, mas que apontam para outros elementos também materiais: o espaço, a visualidade, a legibilidade, a produção.

Essa abordagem é similar e significativa tanto aos argumentos de Ingold quanto à diferenciação materialidade/material de Piquette e Whitehouse. ${ }^{47} \bigcirc$ material, numa noção complementar à de Ingold, não é um elemento que antecede qualquer análise, mas é algo incorporado em "práticas de registro socialmente
39. Knappett $(2007,2012$, 2014).

40. Id., 2007, p. 20

41. Ingold (2007, p. 1)

42. A própria linguagem para definir o que é material e materialidade tende, por força da escrita argumentativa, a ordenar a descrição, dando prioridade ou precedência - $\mathrm{a}$ um ou a outro elemento do aspecto relacional pessoas-objetos antes ou depois (BASU, 2017). Nesse sentido, a linguagem utilizada e o modo sequencial de empregá-la também contam no modo de conceber o que é material e materialidade.

43. Cf. Giddens (1984) e Bourdieu (1994).

44. Remetemos aqui às teorias da agência, especialmente a partir de Art and Agency, de A. Gell (1998), e das conhecidas contribuições de B. Latour (1999; 2005) e J. Law (1992) sobre a Teoria do Ator-Rede, $(A c$ tor-Network Theory, ANT).

45. Balke e Tsouparopoulou (2016, p. 1).

46. Berti et al. (2017).

47. Ingold (2007) e Piquette e Whitehouse (2013). 
48. Piquette e Whitehouse (2013, p. 3).

49. Ingold (2007) e Piquette e Whitehouse (2013).

50. Piquette e Whitehouse (2013).

51. Delnero e Lauinger (2015, p. 9).

52. Karagianni, Schwindt e Tsouparopoulou (2015).

53. Cf. nota 44. Essas e outras abordagens são ampla e variavelmente consideradas pela literatura sobre a materialidade. Remetemos aos panoramas de Trentmann (2009), Knappett (2012), Delnero e Lauinger (2015), Balke e Tsouparopoulou (2016), Karagianni, Schwindt e Tsouparopoulou (2015) e Marcelo Rede. $A$ materialidade e o divino na antiga Mesopotâmia: questões teóricas e possibilidades analíticas. Manuscrito.

54. Marcelo Rede. A materialidade e o divino na antiga Mesopotâmia: questões teóricas e possibilidades analíticas. Manuscrito.

55. Ingold (2010, 2015).

56. Id., 2015, p. 2-3. Seu volume The Life of Lines (2015) se correlaciona a Lines: a brief history, de 2007, e a Making: Anthropology, Archaeology, Art and Architecture, de 2012 (segundo Prefácio de 2015, esp. p. viii-x e, fazendo parte de um projeto mais amplo, o Bringing Things Back to Life, 2010). Consideramos que a partir de The Life of Lines se possam extrair implicações epistemológicas que servem à delimitação da materialidade da escrita como campo de observação de interstícios. Recentemente, o autor avançou na noção de correspondências, também presente no texto de 2015 (Correspondences, 2021). situadas". ${ }^{48}$ Assim, Ingold e Piquette e Whitehouse consideram os materiais como elemento importante para significação da cultura material ${ }^{49}$ Para as autoras, ${ }^{50}$ a conjugação de material e materialidade habilita o material a se tornar ativo para a formação de significado. Por mais corroborativas ou complementares que as visões de Ingold e de Piquette e Whitehouse possam ser, nota-se que a materialidade é o que dá vida ou o que ativa os objetos pelo seu elemento inerentemente social. Essa visão é rejeitada por Ingold, assim como por Delnero e Lauinger, que partem de uma perspectiva relacional entre mundo social e o mundo material, articulando performance, circulação e produção como três espaços sociais em que os textos cuneiformes se movem e funcionam como objetos, constituindo, texto e materialidade, um processo relacional e dinâmico em que modelam e são modeladores do espaço social que circulam. ${ }^{51}$

Karagianni, Schwindt e Tsouparopoulou ${ }^{52}$ estabelecem a relação pessoaobjeto como unidade de sentido para entender tanto a pessoa no mundo material, como a materialidade num mundo de pessoas, partindo da noção coloquial de materialidade (presença física) até a recolocação das experiências humanas em relação aos materiais, destacando as discussões sobre agência material. ${ }^{53}$ As abordagens que consideram a agência material envolvem o reposicionamento heurístico dos dois personagens: ela é secundária ou simétrica àquela humana? Ou a "vida dos objetos" é independente, em menor ou maior grau, da vida dos humanos? Como nos alerta Rede, a busca pelo entendimento da agência material não consiste apenas na tentativa de realocar a agência do humano para objeto, mas sim de uma redefinição mais profunda das relações entre esses agentes:

\footnotetext{
Pela sua própria natureza, a relação social não pode ser assimilada à ação unilateral de um agente. Não é suficiente, porém, oferecer uma corporalidade aos atores, um enquadramento sensorial aos atos e um contexto espacial às atividades. A descrição e a análise de cada uma dessas dimensões significam, por si mesmas, um grande avanço, mas é preciso construir analiticamente uma noção de relação que permita alinhavá-las em um fluxo constante de mutação. ${ }^{54}$
}

Nesse sentido, encontramos em Ingold alguns avanços a partir da noção de in-between, ou "no-entre", que engloba muito mais do que as relações materiais presentes na ideia de materialidade. ${ }^{55} \mathrm{O}$ objetivo principal do autor é reposicionar o enfoque para "os processos de formação, em vez do produto final, e [para os] fluxos e transformações dos materiais, em vez dos estados da matéria". ${ }^{56}$ Assim, coisas e pessoas estão em constante formação e transformação, e é no-entre dos seus processos relacionais que elas adquirem significado. 
A proposta de Ingold apresenta uma divergência sobre as noções comuns de agência e redes de agentes ou redes de sociabilidade, que formam uma ontologia dos objetos e realçam a existência dos materiais e seus papéis relacionais, ou seja, sua materialidade. Contudo, os objetos e sua relação com o ambiente e com os humanos ainda são tratados como se fossem pontos externamente delimitados e articulados, em que estariam o significado e a agência e que passam a ser vistos de modo relacional, em relações de antecedência e sucessão. $\bigcirc$ que Ingold propõe é uma consideração a partir não de articulações entre entidades estáticas, mas sim considerar os objetos, o meio (superfície, ar, atmosfera) e as pessoas como linhas que ocorrem, se transformam e se entrelaçam em nós em uma tessitura de correspondências. Esse tratamento pode revelar, numa perspectiva antropológica, "domínios de pensamento e prática pelos quais padrões de cultura são sustentados e delimitados nos interstícios da vida humana" ${ }^{57}$

Nessa visão as relações materiais são constituídas no fluxo de vida noentre, no viver com objetos e pessoas, no qual há a correspondência, e não por meio de conexões externas e acréscimos (sujeito + objeto). Isso implica a existência como ação dinâmica, um fluir, em constante transformação e em constantes correspondências no ser/estar com, não como estado estático, o que faz da correspondência um continuum de ocorrências e acontecimentos humanos, materiais e atmosféricos. $\bigcirc$ contraste com as perspectivas prévias se dá na consideração de pressuposições, de entidades e existências que depois se encontram e se articulam. Como destacam Basu e Rede, ${ }^{58}$ o no-entre reverte a tendência essencialista da epistemologia ocidental, que distingue coisas e, consequentemente, separa sua existência. A vida das linhas, que porta as correspondências que ocorrem nos interstícios entre as coisas, é existência que se faz, no contínuo, entre o não-ainda e o já-aqui. $\bigcirc$ significado e a agência, então, são reconhecidos como elementos que se fazem no-entre das correspondências entre objetos, sujeitos e meio. Pensando na materialidade da escrita cuneiforme, podemos evocar o sentido da relação entre mão e argila, na forma mãos na argila. $\bigcirc$ texto-mensagem do tablete cuneiforme é somente uma faceta de sentido de um fluxo intersticial do escriba e da argila. A argila modelada como tablete, o tablete pronto e o tablete escrito são fases do fluxo de vida da argila.

\section{Materialidade em contexto}

Embora seja importante nos debruçarmos sobre o que entendemos por materialidade e as possibilidades para sua abordagem, uma compreensão sobre
58. Basu (2017, p. 2) e Marcelo Rede, $A$ materialidade $e$ o divino na antiga Mesopotâmia: questões teóricas e possibilidades analíticas. Manuscrito. 
59. Meskell (2005, p. 6).

60. Tilley (2007, p. 20).

61. Glassner (2000, p. 21).

62. Pearce (2010).

63. Cf. os Cilindros de Gudea, em: <https://bit. ly/3EgN4OP $>$. Num longo trecho no qual consta uma adoração à deusa Nanshe, pedindo bons augúrios $\mathrm{e}$ proteção, Gudea pede a interpretação de um sonho, em que uma mulher, com um stylus de prata, consulta as estrelas; no mesmo sonho, um homem-guerreiro aparece, segurando um tablete feito de lápis-lazúli, onde escreve a planta de uma casa. Nanshe lhe explica que a figura feminina é sua irmã, Nisaba, enquanto o guerreiro é Nindub, literalmente o senhor do tablete. Veja também o hino paleobabilônico à Nisaba, divindade associada à prática dos escribas. Cf. <https://bit.ly/3hmQUvM>.

64. A versão completa desse poema e os estudos detalhados podem ser encontrados em Kramer (1952), Cohen (1973) e Vanstiphout (2003).

65. Nossa tradução das linhas 502 a 506 do texto é baseada em Vanstiphout (2003, p. 84) e Verderame (2016). os significados da materialidade não pode ser reduzida "a um conjunto de condições dadas ou práticas comuns de todas as culturas e todos os tempos". ${ }^{59}$ Para lidar com a materialidade dos objetos, é necessário recolocá-los, bem como suas propriedades, em seus próprios fluxos e no relacionamento recursivo entre pessoas e coisas num mundo material específico, de diferentes lugares e tempos, e significado de modos diversos por esses sujeitos em seus próprios contextos. 60 Nesse sentido, damos um primeiro passo em direção ao contexto mesopotâmico, por meio de relatos literários e fontes iconográficas, ao observar a atenção dada ao material sobre o qual se escrevia, uma perspectiva que se relaciona diretamente à noção de materialidade.

A escrita aparece frequentemente como tema da literatura mesopotâmica associada à divindade ou mesmo à sua origem e materialização como criação humana. ${ }^{61}$ Por exemplo, Pearce ${ }^{62}$ recolhe várias ocorrências em diferentes textos literários que mencionam materiais de prestígio utilizados para a escrita, como nos diferentes relatos da dimensão divinatória com a presença de divindades. Em alguns casos, está presente o pedido à divindade para que explique ou registre em tabletes os sinais expressados pelos movimentos dos corpos celestes. A partir da contribuição de Pearce, tais menções literárias à escrita são vistas pela ótica da materialidade, sobretudo por meio de objetos excepcionais, ${ }^{63}$ necessários para registrar um conteúdo extraordinário. A escrita como um ato de criação humana é mencionada no excerto do poema épico conhecido por Enmerkar e o senhor de Aratta. ${ }^{64} \mathrm{Em}$ meio a uma disputa entre Enmerkar, rei de Uruk, e o senhor de Aratta, uma série de mensagens orais são trocadas. Em um dado momento, o mensageiro não dá conta de reter as palavras que deveria transmitir. Como solução, Enmerkar transforma a argila em tablete e grava suas palavras para que elas não sejam esquecidas no percurso.

Porque a boca do mensageiro estava muito pesada, e ele não podia repetila,

o senhor de Kulab bateu um pouco de argila e colocou as palavras sobre isso como se fosse um tablete.

Antes desse dia, não havia palavras colocadas sobre a argila;

mas agora, quando naquele dia o sol [lit. deus Utu] surgiu, assim foi:

o senhor de Kulab havia colocado as palavras sobre a argila! ${ }^{65}$

Assim, o surgimento da escrita como ato humano estaria aliado à necessidade de tornar a comunicação eficiente. 
Nas representações iconográficas também se observa o lugar da escrita por meio de suas ferramentas. Dentre as fontes iconográficas disponíveis que apresentam o instrumento de escrita cuneiforme (o stylus), há representações simbólicas do deus Nabû, divindade assírio-babilônica associada à prática dos escribas. ${ }^{66}$ As ocorrências, em estelas, pedras de fronteira e selos cilíndricos, em geral, aparecem na representação de um objeto, em muitos casos semelhante à forma de uma cunha, mormente na posição vertical (Figura 1).

Além dessas fontes, encontra-se o stylus relacionado à própria função da escritura. Sem contar com imagens mais recentes (do primeiro milênio AEC) de sujeitos segurando um suporte para escrita numa das mãos e na outra o stylus, há dois casos mais recuados com a imagem do instrumento de escrita em situações e formas desproporcionais. No primeiro caso, numa estela do período de Ur III (séc. XXII-XXI AEC), há uma cena fragmentada (Figura 2) de um sujeito segurando com ambas as mãos um grande suporte, enquanto outra pessoa, sentada (posição que pode indicar sua qualidade divina ou de grande status), utiliza um instrumento alongado e visível e que está em contato com aquela superfície (possivelmente para imprimir algo nela). Já no segundo caso (Figura 3), o conhecido pedestal de Nusku, do período de reinado do assírio Tukulti-Ninurta I (ca. 1233-1 197 AEC), a figura do rei é esculpida em dois momentos (em pé e em genuflexão, em ambos assumindo uma posição de adoração) diante de um patamar (provavelmente um altar), no qual estão apoiados um objeto quadrangular (provavelmente um tablete) e um instrumento longilíneo e fino, sobre o qual se debate se é um stylus ou um cetro. Guardadas as especulações interpretativas, esses casos recuperados por Cammarosano de ocorrências do instrumento de escrita em fontes mesopotâmicas de cultura material também chamam a atenção para possíveis significados do stylus (bem como do tablete), associados à aproximação ao universo além do terreno. 


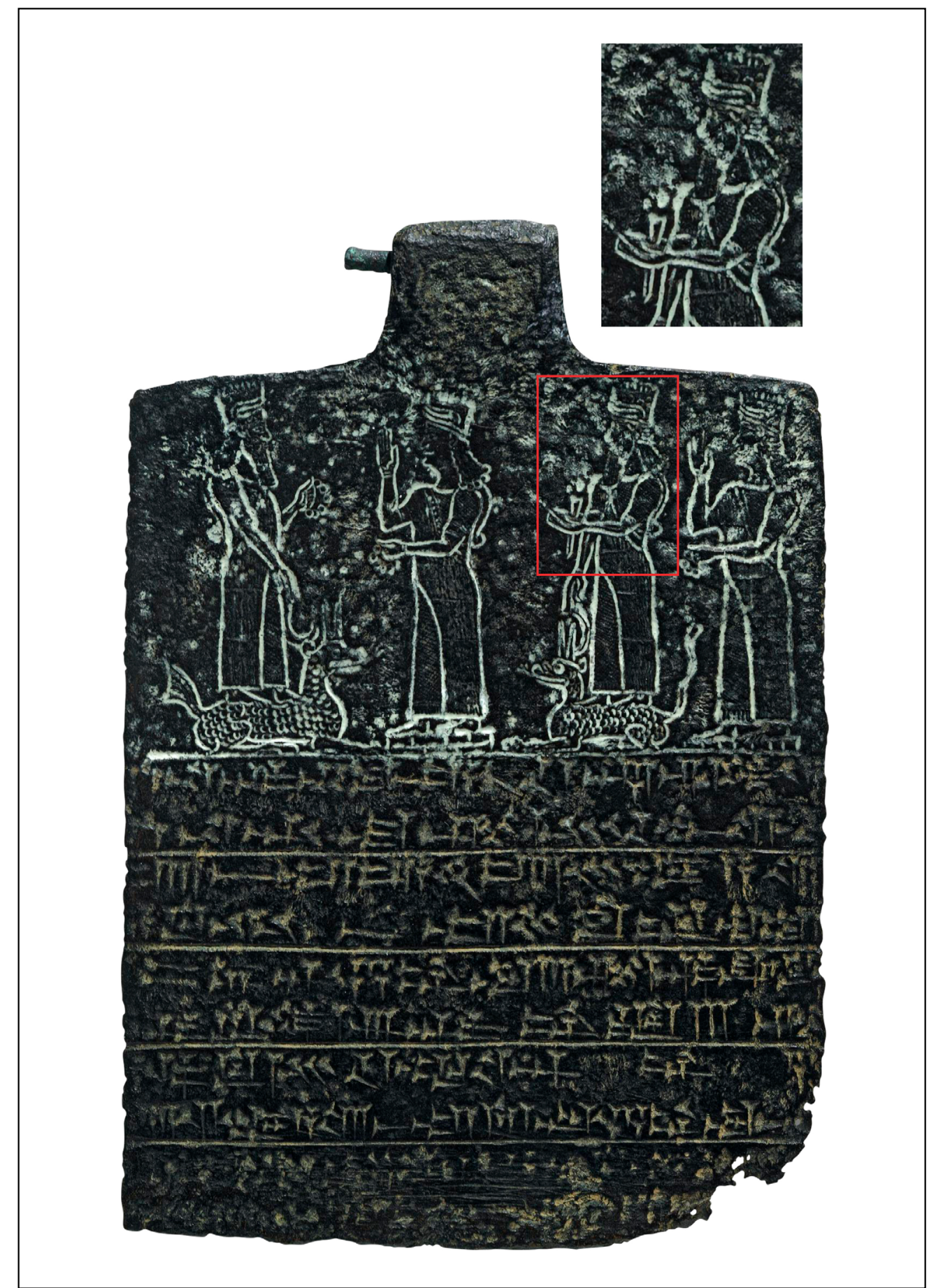

Figura 1 - Placa votiva, em cobre. Templo de Nabû, Nimrud/Kalhu (sécs. IX-VIII AEC). O detalhe realçado em vermelho mostra a representação de uma figura que segura um tablete e um stylus, este em formato similar a uma cunha vertical da escrita cuneiforme. Fonte: (CThe Trustees of the British Museum (BM 1 18796). 


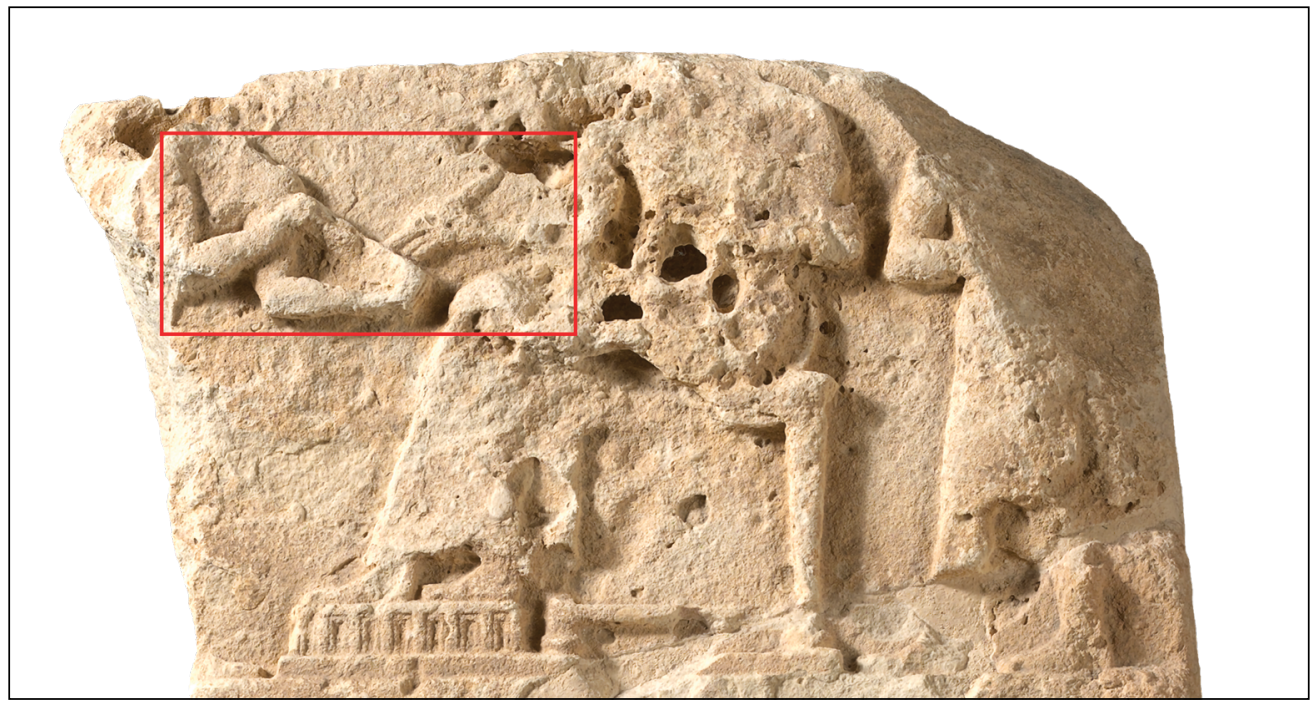

Figura 2 - Fragmento de estela. Realce em vermelho: à esquerda, membros superiores de uma figura humana seguram objeto sobre o qual, outra figura humana, sentada, parece apoiar um objeto alongado. Fonte: (c) Staatlichen Museen zu Berlin-Vorderasiatisches Museum (VA 07245), Foto: Olaf M. Teßmer.

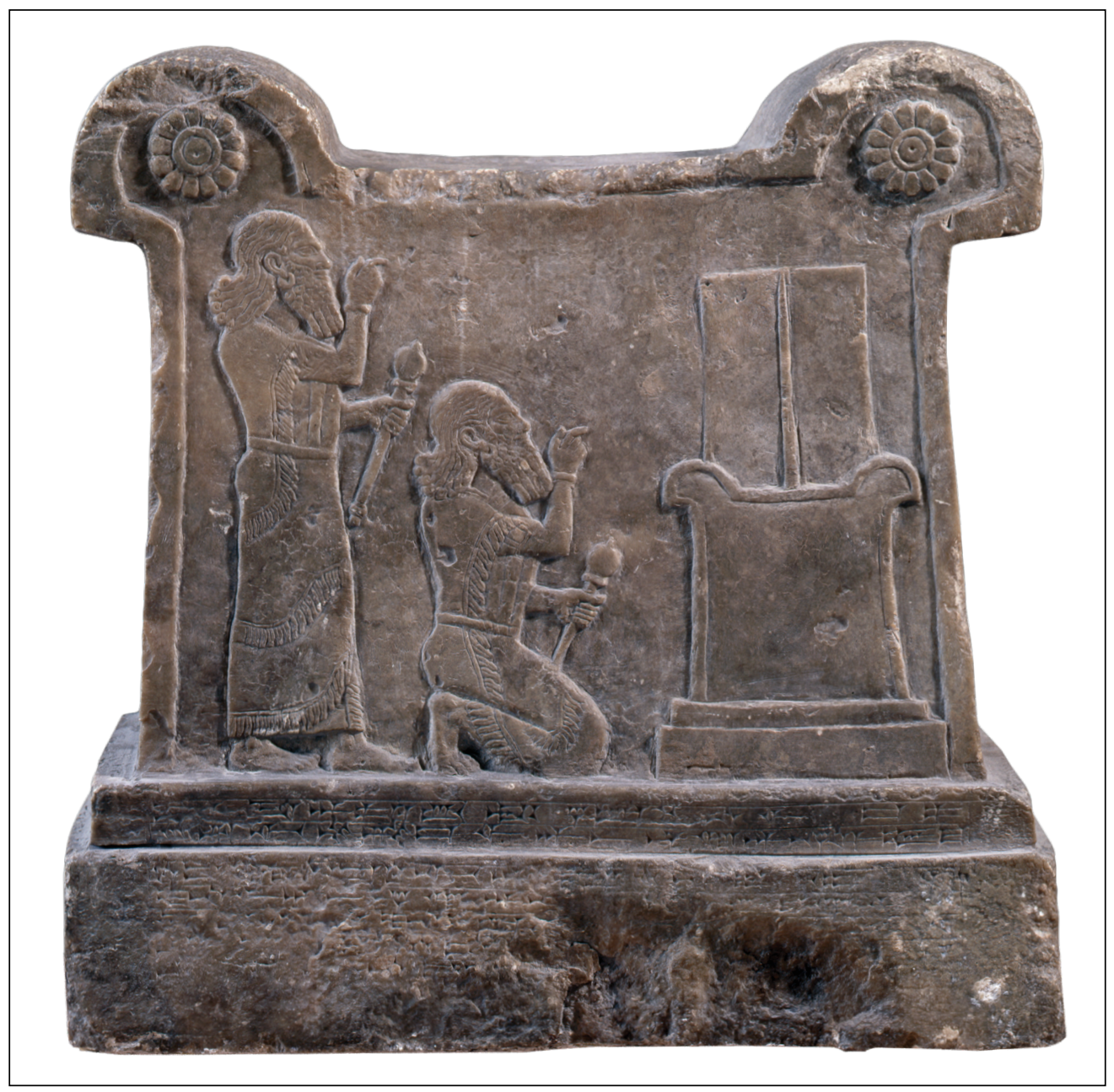

Figura 3 - Pedestal de Nusku, séc. XIII-XII AEC. Fonte: (C) Staatlichen Museen zu Berlin-Vorderasiatisches Museum (VA 08 146). Foto: Olaf M. Teßmer. 
67. Pearce (2010)

68. Para uma introdução ao pano de fundo de formação do conhecimento mesopotâmico, da forma pela qual, em sua concepção mitológica, foi originado a partir da inspiração divina e foi preservado pelos escribas eruditos (culminando nos escribas do alto escalão assírio do $1^{\circ}$ milênio AEC) (PARPOLA, 2014, p. XIII-XXXV).

69. Matthews (2013).

70. A concepção de adivinhação mesopotâmica contempla, a partir da tradição babilônica e assíria, a consulta ao deus da justiça, Shamash, que inscreveu no mundo os sinais daquilo que pode ser interpretado. Assim, não só o céu, mas fenômenos da natureza, sonhos e corpos (animais e humano) são passíveis de estarem inscritos com sinais ominosos.

71. Pearce (2010, p. 177).

72. Ibid.

73. O tablete de argila é um objeto que precede o surgimento da escrita cuneiforme. Então, apesar de ser o principal suporte utilizado pelo cuneiforme, o tablete não é, em si, um dispositivo exclusivamente linguístico, mas comportou e foi comportado por fases de desenvolvimento da complexidade social e urbana, que por sua vez empregaram inovações na dimensão cognitiva. Sobre isso, cf. Rede (1998-1999).
Retomando Pearce, ${ }^{67}$ a imagem dos implementos de escrita lo tablete e o stylus) é explorada em textos literários mesopotâmicos, destacando as ocorrências e atribuindo sentido extraterreno a esses objetos, devido ao seu tamanho e seu material. Apesar de sua argumentação estar calcada numa abordagem linguística, tratando os materiais como significantes, Pearce aponta o prestígio da escrita e do conhecimento inscrito por meio: (1) da materialidade do objeto inscrito, envolvendo pedras especiais ou metais, e do objeto/instrumento de escrita; (2) da associação da escrita a uma prática e a um conhecimento divino, relacionado ao desenvolvimento do conhecimento terreno; 68 e (3) da função do objeto inscrito em determinados espaços (fundações de edifícios e "bibliotecas", também apontados por Matthews ${ }^{69}$ ).

Os exemplos levantados pela autora destacam que as menções textuais ao uso de materiais de prestígio (tratados como significantes) realçam o valor do conhecimento tradicional, em paralelo ao conteúdo e muitas vezes ao arranjo espacial do texto (como é o caso emblemático das inscrições de fundação, colocadas na base das paredes de grandes construções, como os palácios). Além disso, a escrita também aparece associada a conceitos cosmológicos, como é o caso da materialidade da "escrita do céu". 70 Em acadiano, shitir shamê, "[...] era um meio lúcido e altamente ordenado e padronizado de comunicação e mediação entre os reinos do divino e do humano", 71 em que um deus convertia as imagens das estrelas, gravadas num tablete, em mensagem para os seres humanos de status elevado, que implementariam no plano terreno o conhecimento adquirido.

Há também as menções ao cuidado no preparo do tablete, desde a escrita do texto até a sua colocação/disposição num dado espaço (mesmo que seja invisívell. Segundo Pearce, ${ }^{72}$ apesar de paradoxais, as menções à escrita com stylus em um tablete de pedra adicionam valor simbólico à atividade, mesmo que a materialidade destoe da prática de escrita comum. Portanto, esses casos recolhidos pela autora sustentam uma interpretação da importância tanto da materialidade da escrita na cultura mesopotâmica, como da materialidade do conhecimento, o que atribui um poder ao objeto inscrito.

\section{A materialidade dos tabletes cuneiformes}

Ainda em busca de recolocar a materialidade a partir de sua produção e circulação, abordaremos o contexto mesopotâmico procurando mostrar o caminho da composição de um tablete, visando entender quais componentes envolvem sua materialização. Em seguida, por meio de exemplos, trataremos das implicações sociais e culturais dos tabletes de argila. ${ }^{73}$ 
Frequentemente, a tridimensionalidade dos tabletes é ignorada, seja pela dificuldade de acesso às coleções museológicas (onde se encontra grande parte dessa documentação), seja pela preocupação exclusiva com o conteúdo do texto. Replicados e analisados em um espaço bidimensional por meio de fotos, cópias, ${ }^{74}$ publicações da transliteração, ou apenas acesso à tradução do texto, são abordados pelo "[...] conteúdo apresentado como uma abstração que existe à parte do meio que aparece" ${ }^{75}$ Como consequência, isso significa separar

[...] o conteúdo de um texto de seu ancoramento espacial e temporal imediato, de modo que ele se torne uma abstração estática, imutável, que pode ser estudada como um sistema fixo e autocontido de significado, removido da dinâmica do mundo social em que foi produzido e circulado. ${ }^{76}$

Esses tabletes eram formulados marcando os sinais de escrita cuneiforme na argila molhada, pressionando um instrumento chamado stylus em sua superfície. Os styli tinham a ponta com o formato de um cone poliédrico. Já as cunhas tinham forma de tetraedros. $\bigcirc$ nome desse instrumento é, em acadiano, qan tuppi e, em língua suméria, gi.du.ba, que significa, literalmente, cana de tablete, o que levou por muito tempo à crença de que o stylus era feito desse material, uma planta conhecida como cana-do-reino (Arundo donax). ${ }^{77}$ Estudos recentes defendem que o stylus poderia ser feito de outros materiais, como ossos e metais. ${ }^{78}$ Para Cammarosano, ${ }^{79}$ a escassez de vestígios arqueológicos não deve ser atribuída apenas à natureza biodegradável das plantas, mas ao fato de que objetos de metal ou osso, pequenos e não decorados, não eram pensados como instrumentos de escrita nos contextos arqueológicos e podem ter sido ignorados durante as escavações.

A argila mesopotâmica ${ }^{80}$ era uma matéria prima de fácil obtenção nesse contexto, tendo como principal característica a plasticidade e é por isso que podemos encontrar tabletes modelados em diversos formatos e tamanhos, que variam de $1,6 \mathrm{~cm} \times 1,6 \mathrm{~cm}$ e espessura de $1,1 \mathrm{~cm}$ a $36 \mathrm{~cm}$ (altura) $\times 33 \mathrm{~cm}$ (largura) e $5 \mathrm{~cm}$ de espessura. ${ }^{81}$ Apesar da variedade de formas e tamanhos, a maioria tem pequenas dimensões, cabendo na palma de uma mão. De maneira geral, podemos dizer que o formato está relacionado ao conteúdo, ao local e ao período de produção. ${ }^{82}$ Outra importante característica da plasticidade da argila é permitir que o mesmo material pudesse ser reutilizado várias vezes e de maneiras diferentes, inclusive utilizando um tablete ainda úmido para se produzir um novo tablete ${ }^{83}$ ou, mesmo seco, utilizá-lo em construções integrando o pavimento de um edifício. ${ }^{84}$

A maioria dos tabletes era submetida à secagem ao sol, e apenas em casos de armazenamento permanente ocorria o cozimento intencional em altas
74. Representações gráficas e bidimensionais dos sinais que foram impressos nos tabletes.

75. Delnero e Lauinger (2015, p. 1-2).

76. Ibid.

77. Cammarosano (2014, p. 53).

78. Cf. Cammarosano (2014) e Bramanti (2015).

79. Cammarosano (2014, p. 62-63, 84).

80. A argila mesopotâmica era do tipo montmorilonita (MMT), segundo Balke et al. (2015, p. 277).

81. Balke et al. (2015, p. 281). É válido destacar "tabletes" ainda maiores, mas com usos e materialidades distintos, como é o caso do Tratado de Sucessão de Esarhaddon (de 672 AEC), ou de todos os textos conservados na dita "biblioteca de Assurbanipal" (669630 AEC).

82. Sobre a manufatura dos tabletes e a relação entre forma e conteúdo, Cf. Radner (1995) e Taylor (2011).

83. A plasticidade dos tabletes úmidos ainda pode ser vista a partir de intervenções menores no material, especialmente em casos de tabletes usados em escolas de escribas ( $\mathrm{e}_{2}$.dub.ba, edu$b b a)$, quando erros durante exercícios podiam ser "apagados" com os dedos ou deslizando algum instrumento (provavelmente o corpo do stylus), renovando a totalidade de uma das faces do tablete. Veja o caso excepcional de um tablete escolar com "rabiscos" de uma figura humana. Cf. $<$ https://bit.ly/3z5R2FY> (TINNEY, 1998).

84. Sobre a reutilização dos tabletes, cf. Faivre (1995) e Taylor e Cartwright (2011). 
85. Brookes (1997, p. 203).

86. Como, por exemplo, o corpus de tabletes em linear B preservados do período micênico (séc. XVI-XIII AEC) da região do mar Egeu, também fruto de um incêndio. Nesse caso, nos termos de Finley (1990), o corpus preservado pelo incêndio é um "corte transversal" na temporalidade e espacialidade do contexto dos palácios.

87. Cf. Organ (1961) e Brookes (1997). E, segundo George (1999, p. 210), há outras deformações dos tabletes, posteriores à confecção e secagem, causadas tanto por acidente com picaretas durante as escavações como por minhocas no solo.

88. Bramanti (2005, p. 2-3) e Cammarosano (2014, p. 60, 74-79).

89. Bramanti (2005, p. 4) e Cammarosano (2014, p. 79). temperaturas, aumentando sua vida útil quase ilimitadamente. ${ }^{85} \mathrm{Em}$ vista disso, é válido acrescentar que casos de incêndio também levaram à queima não intencional dos tabletes. ${ }^{86}$ Após gravados na superfície úmida da argila, os sinais podem sofrer contração durante a secagem ou diversas reações devido à ação do tempo. No caso dos tabletes que não foram submetidos à secagem em altas temperaturas, a argila torna-se instável ao entrar em contato com a água, podendo amolecer e se desconfigurar. Além disso, em razão da presença de sais solúveis, tanto na composição da argila quanto no solo onde os tabletes eram depositados, podemos observar a migração e cristalização mineral para sua superfície, o que causa escurecimento, descamação e fissuras. ${ }^{87}$

Indo além das propriedades dos materiais, materializar a escrita envolve a realização ou performance, como é chamada na literatura, de quem escreve, uma ação corporal específica para cunhar os sinais na argila. Duas teorias se destacaram ao tratar dessa realização a partir das formas de empunhar o instrumento de escrita e gravar os sinais sobre a argila. A primeira, e mais tradicional, defende que um objeto comprido era segurado com a mão, com a palma total ou parcialmente voltada para baixo (de uma maneira semelhante a que escrevemos hoje); a segunda defende que um objeto pequeno era sustentado entre o polegar e o indicador. Em ambos os casos, se poderia também segurar o stylus em posição de supino (com a palma da mão quase completamente voltada para cima), opção que parece exigir um esforço físico menor e agilizaria o processo, já que o punho executaria movimentos mais finos e facilitaria ainda a alternância da impressão de cunhas verticais, horizontais e cabeças de cunha. Além disso, o stylus curto parece mais fácil de ser segurado. ${ }^{88}$ Como ação prática, a performance de quem escreve não compila a complexidade da materialização da escrita, assim como ela não pode ser reduzida apenas à gravação de sinais. A performance é finita e está fixada no passado, mas o resultado congela-se no tempo por meio da materialidade dos tabletes.

Portanto, um texto gravado em um tablete depende da interação complexa entre a dimensão material e humana: da superfície de escrita - a umidade e qualidade da argila; do material escolhido como stylus e a sua fabricação; da interação entre o punho (posição e inclinação do gesto), o stylus e a superfície de escrita; da interação entre as cunhas que formam o texto e da alteração que o texto escrito na argila pode sofrer após ser impresso; 89 até a interação do material escrito com o meio ambiente no qual é disposto.

Bramanti propõe uma análise da "materialidade do cuneiforme" lla materialità del cuneiformel a partir das contribuições da "diplomática" textual, metodologia bastante utilizada em estudos medievais, mas que tem servido ao tratamento de manuscritos antigos em geral. Uma síntese dos elementos considerados 
por esse procedimento é útil para se observar quais características são englobadas na noção de materialidade da escrita: o formato, a dimensão, o tipo de material, a disposição/orientação do objeto/do texto, a repartição interna do texto, a dimensão dos sinais, os instrumentos empregados na escrita, os elementos não textuais (selos e colofão anepigráficos, marca de unhas e roupas); a datação, a proveniência, o conteúdo, o contexto, a presença de elementos arcaicos ou arcaizantes, as particularidades e idiossincrasias do objeto/texto (escolas e escribas; uso de variantes e ordem fixa de sinais), entre outros. ${ }^{90}$

Nos termos de Bramanti, ${ }^{91}$ uma análise meta-textual do tablete cuneiforme é essencial para qualquer trabalho profissional com documentos que se valeram desse sistema de escrita, especialmente, no caso de um corpus ainda não editado, favorecendo a compreensão de facetas do contexto em que esse corpus foi produzido. Contudo, existem ainda dois estágios a se considerar a partir de metodologias complementares: de um lado, a análise meta-textual acaba por retornar ao textual, atrelando contexto a conteúdo, sendo, portanto, importante considerar as relações materiais (e não só textuais) do objeto inscrito no contexto. Por outro lado, é preciso compreender o objeto como uma materialidade em meio a outras relações e que afeta e é afetado pela dinâmica do social.

A título de exemplo, Verderame propõe uma abordagem holística ao estudo das inscrições provenientes do templo de Inanna em Nippur, datadas do período Dinástico Recente (2900-2350 AEC), contemplando a relação entre texto, contexto e dimensão social. A popularidade do culto e de seu local pode ser depreendida a partir dos tipos e padrões de deposição de inscrição (em objetos específicos), que também revelam a relação do culto com o contexto social (perfil social e de gênero). ${ }^{92}$

Essas considerações sobre a materialidade, em conjunto, correspondem, segundo Matthews, ${ }^{93}$ a um redirecionamento metodológico que toma a leitura e a escrita como práticas materiais. Esse novo aporte tendeu a diferentes vertentes de pesquisa: inclusão do interesse pela forma física do tablete e do instrumento de escrita; aparência do texto; uso de selos; aplicação de métodos arqueométricos de análise, permitindo, por exemplo, que se descobrisse a constituição e local de origem da argila; os elementos sociais da escrita, implicando interesses pela intenção do autor e a produção do próprio tablete; uma abordagem à variedade das funções da escrita de seu surgimento até sua expansão de uso; o nível de letramento, articulado a modos de controle e imposição (na forma de uma rede vertical) e de amplitude e dispersão (uma rede horizontal), formas que sustentam o texto no tempo e no espaço e que dependem de sua materialidade; audiência e acessibilidade aos textos; contexto de obsolescência da escrita; por fim, a trajetória do textos, contingenciada e especificada por sua materialidade, desde a 
94. Ibid., p. 72-73.

95. O exemplo apresentado nessa subseção parte da ampla análise de 50 cartas administrativas que integram a pesquisa de mestrado da autora, Anita Fattori, intitulada 50 Cartas de Tell Harmal: Práticas Administrativas e Sociabilidade no Antigo Reino de Eshnunna (FATTORI, 2019). A pesquisa foi realizada com bolsa da Fundação de Amparo à Pesquisa do Estado de São Paulo (Fapesp, processo ${ }^{\circ}$ 2016/07059-9 e processo $\mathrm{n}^{\circ}$ 2016/22988-6).

96. Hussein (2009, p. 337).

97. As cartas mencionadas neste artigo serão referenciadas pelo seu número de registro no Museu Nacional do Iraque (Iraq Museum, IM). A primeira edição dessas cartas está em Götze (1958). As traduções em português de um conjunto dessas cartas estão em Fattori (2019).

98. Nosso contato com essa documentação só é possível por meio das cópias com o desenho das superfícies dos tabletes, que foram publicadas por A. Götze (1958). Apesar de serem cópias e de não sabermos o estado atual desses tabletes, conseguimos prever com segurança suas características materiais com o auxílio de outros contextos arqueológicos similares. A partir desses materiais podemos inferir sobre o formato retangular do tablete, seu envelope de argila, o tamanho dos sinais e das linhas impressas no tablete. $\mathrm{Na}$ sequência deste estudo de caso, veremos que a materialidade do tablete e a materialidade do texto nos habilitarão a compreender a dinâmica dos tabletes nesse contexto administrativo de Eshnunna. preparação da argila à "agência" da função do texto finalizado. Por fim, na visão de Matthews, ${ }^{94}$ seria profícuo integrar "perspectivas materiais, arqueológicas e filológicas", incluindo fontes e processo de manufatura dos tabletes, a relação entre materialidade e contexto com as diferenças de suporte para escrita e a importância dos tipos de textos e suas relações com o contexto social antigo.

\section{ESTUDOS DE CASO: MATERIALIDADE DA ESCRITA CUNEIFORME}

\section{A vida social dos tabletes: as cartas administrativas de Shaduppûm ${ }^{95}$}

Como vimos, os tabletes de argila são a maior fonte para os estudos de história da Mesopotâmia e impressionam não apenas pela quantidade, mas pela variedade de formas, conteúdos e contextos de circulação. No sítio arqueológico de Tell Harmal, antiga Shaduppûm, localizada na atual cidade de Bagdá, foram escavados e datados (início do segundo milênio AEC) cerca de 3 mil tabletes de argila de cunho administrativo, 96 dos quais destacamos algumas dezenas de cartas intercambiadas entre os oficiais da administração da região. ${ }^{97}$

A análise desse estudo de caso discute a importância dos tabletes de argila, a sua produção e sua circulação em um contexto administrativo específico do chamado período paleobabilônico (2003-1595 AEC), mais precisamente o período que compreende a primeira metade do século XVIII AEC. Para além de uma definição cronológica, o termo paleobabilônico se refere ao dialeto da língua acadiana que emerge no Sul da Mesopotâmia nesse período. Em um quadro geral, no período de produção dessas cartas, Shaduppûm desempenhava a função de centro administrativo de um distrito agrícola e era parte de um reino central na região do vale do rio Diyala, o reino de Eshnunna.

A preparação dessas cartas envolvia, primeiro, a modelagem da argila, em formato retangular, e, após a gravação do texto lação que dependia da interação material-humano), recebiam um envelope, também em argila para finalmente serem transportadas ao destino. Ao chegarem, os envelopes eram abertos - processo que, por muitas vezes, levava a sua destruição, parcial ou completa - e o texto era lido pelo ou para o seu destinatário. ${ }^{98}$

A princípio, podemos pensar nos elementos textuais dessa documentação. Em relação a seu conteúdo, elas tratam majoritariamente da gestão das terras agrícolas e de suas consequentes demandas, como a gerência de pessoas, 
informação e bens, a exemplo de animais e grãos, principalmente cevada. Distante de toda estrutura e aparato burocrático oferecido pelo palácio de Eshnunna, os administradores de Shaduppûm - alguns em constante deslocamento pelas terras agrícolas da região - necessitavam acessar, mesmo que de maneira instrumental, a escrita cuneiforme, uma habilidade essencial para lidar com o registro do conteúdo e o processamento e comunicação de informações que eram circuladas nesse contexto. ${ }^{99}$ Nesse sentido, pessoas e coisas interagiam dentro de um sistema no qual estavam imersas e habilitadas. A presença da comunicação epistolar nesse sistema implicaria uma estrutura administrativa que sustentasse também redes de comunicação.

Apesar de não haver elementos suficientes para afirmar as ações dos destinatários após o recebimento das cartas, o conteúdo das mensagens permite observar a interação entre remetente e destinatário. Nessa rede de comunicação epistolar formada em meio às práticas administrativas, encontramos alguns marcadores de interações sociais específicas, como o emprego constante pelo remetente de verbos no imperativo, de fórmulas que expressavam questionamentos, apelos, pedidos ou ordens, ou de perguntas retóricas, como veremos a seguir: "Envia-o rapidamente" (IM 51 186: 17-18); "Rapidamente dá (a cevada) para ele" (IM 51321:9-10); "[...] tu não me trouxeste prata, nem me deste tua explicação" (IM 51376:4-5); "Se o campo está irrigado ou não irrigado, escreva-me" (IM 51 192:3-5); "Por que razão eles escrevem para ti em relação à cevada, mas tu não dás nenhuma cevada?" (IM 51 226:4-6). Nesses excertos, nos parece claro que o remetente buscava persuadir seu destinatário a realizar uma ação desejada. Carregariam, então, as cartas uma intencionalidade embutida pelos remetentes?

Se tomarmos as cartas como veículos de conteúdo, elas funcionariam como ferramentas administrativas, o que Ingold define como simples "objeto[s] que estende[m] a capacidade de um agente [o remetente] de operar dentro de um dado ambiente". ${ }^{100}$ Assim, o remetente poderia transferir suas intenções para o tablete, gravando os sinais na argila, e o tablete carregaria as informações que circulariam nesse contexto, transportando um texto que comunica, quase de forma automática, uma mensagem. Esse é um cenário que ilustra uma realidade fixa e previsível, atribuindo papéis determinados aos tabletes nesse contexto. Nessa perspectiva, a agência material estaria delimitada à agência humana, ou seja, os tabletes seriam portadores de uma agência secundária, transposta do remetente (sujeito) para a carta (objeto) durante o momento da escrita.

Todavia, mesmo que os remetentes se apropriem de uma linguagem específica com o intuito de obter as respostas desejadas de seus interlocutores, " $[. .$. quem escreve uma carta sabe que a escrita não dá conta automaticamente de mover uma pessoa de lugar". ${ }^{101}$ Ou seja, uma carta não transmite uma mensagem
99. O entendimento de como o letramento se estabelece dentro da cultura cuneiforme é campo de disputa entre os assiriólogos. Aproximando-se de uma noção de níveis de letramento, da qual compartilhamos, vários autores, como Charpin (2010) e Veldhuis (2011), buscam nuançar a dicotomia entre letrados, os que receberam uma educação em ambientes institucionalizados, e iletrados, que não tiveram educação em escolas de escribas (FATTORI, 2019, p. 102-104).

100. Ingold (2000, p. 315). 101. Fattori, op. cit., p. 116. 
102. Steadman e Ross (2010, p. 5) e Tilley (1989, p. $188 ; 2007$, p. 20 ).

103. Nesse trecho, se traduzido literalmente, encontraríamos duas expressões idiomáticas da língua acadiana: "Até agora eu não comi tuas tâmaras. Teus espinhos perfuram meus rins". A primeira delas, "comer as tâmaras" de alguém, tem o sentido de "tomar vantagem de alguém" (Göetze, 1958, p. 31). Já a segunda expressão apresenta a palavra rim como elemento central: na cultura mesopotâmica, os rins estariam conectados aos sentimentos de uma pessoa. Portanto, podemos entender essa frase como "tu machucaste os meus sentimentos".

104. Ingold (2015, p. 152).

105. O exemplo apresentado nessa subseção é baseado na pesquisa de doutorado de Leandro Ranieri, intitulada Concepções de corpo na Assíria do primeiro milênio a.C.: entre materialidade e textualidade (Ranieri, 2018). A pesquisa foi realizada com bolsa da Fundação de Amparo à Pesquisa do Estado de São Paulo (Fapesp, processo $\mathrm{n}^{\circ}$ 2014/22125-2 e processo $\mathrm{n}^{\circ}$ 2016/02441-2).

106. Cf., por exemplo, os estudos em Berti et al. (2017). congelada no tempo, nem o seu texto é o seu fim em si mesmo. Como parte das redes administrativas, sua definição extrapola os questionamentos em torno do que as coisas podem fazer por nós, da atribuição de papéis exatos e imutáveis que nós, humanos, pensamos poder thes assegurar. Como, então, a materialidade afeta essa realidade? A única forma de entender sua completude é inseri-las de volta em seus fluxos, entendê-las como participantes ativas dessa sociedade. ${ }^{102}$

Ainda que o letramento seja um privilégio de determinados grupos sociais na antiga Babilônia (segundo milênio antes de nossa era), a escrita e sua materialidade não se restringem a um instrumento de poder, nem ao registro e transporte de operações administrativas pragmáticas. As cartas garantem, em vez disso, a rede de comunicação, são sua substância e materialidade da comunicação. Entretanto, existe um limite e uma imprevisibilidade em como as cartas podem afetar a rede administrativa, como podemos observar nas acusações dos remetentes: "Eu não fui desleal contigo, [mas] tu machucaste meus sentimentos"103 (IM 51 226:7-1 1); "Está certo se tu distorces as minhas palavras?" (IM 51 192:21-24). Além do ato de negligenciar um pedido por parte de um destinatário (não é de hoje a acusação de "não recebi sua mensagem"), uma carta também pode se quebrar durante o transporte.

A vida da argila é dinâmica. As mãos na argila a fazem tablete. O tablete se torna carta quando exerce suas potencialidades durante a escrita, o transporte, a recepção, o manuseio, a leitura, o armazenamento, enfim, afetando e sendo afetado no-entre (in-between) dessa rede. Os administradores de Shaddupûm e as cartas respondem e são responsivos uns aos outros, num fluxo múltiplo que comporta as correspondências desses sujeitos pelas suas relações funcionais na rede administrativa, pela mensagem escrita e pela materialidade dessas relações com - tablete. E é o contínuo "[...] devir de coisas e pessoas no fluxo de correspondências" 104 que permite e possibilita a produção, reprodução e o estabelecimento de redes de comunicação dentro das redes administrativas.

\section{Uma outra materialidade: a complementaridade texto-imagem nas paredes palacianas $^{105}$}

Um outro campo ou contexto característico de implementação da escrita no recorte mesopotâmico é a escrita monumental. A presença de inscrições em monumentos não é uma particularidade do cenário próximo-oriental; 106 contudo, é característico da escultura monumental o seu eixo de produção fixado no centro palaciano e na figura do rei: o palácio estimula a produção de grande parte da 
comunicação oficial do período, sejam cartas, sejam inscrições reais. Apesar de aqui discutirmos a dimensão material dos tabletes cuneiformes, uma apresentação breve da relação entre texto e imagem em obras monumentais palacianas serve como estímulo para se observar o sentido amplo da materialidade da escrita e os problemas que ela pode exigir às pesquisas.

Em geral, a estrutura palaciana sustentava um grande aparato comunicativo, exigindo a capacidade de ler e escrever por parte daqueles que transitavam e se relacionavam com essa organização, o que constituía ainda elemento importante da formação e consolidação dos reinos no Antigo Oriente Próximo. Isso nos remete a Matthews, ${ }^{107}$ que lembra um aspecto da materialidade dos objetos inscritos, o uso da escrita para exercer imposição, controle e domínio, numa rede vertical de relações sociais, em que os detentores de saberes e práticas estão acima dos demais. Balke e Tsouparopoulou afirmam que os textos palacianos são uma propriedade da realeza e do próprio palácio, especialmente aqueles dispostos no interior desse ambiente. Assim, pode-se considerar "o texto como produto social de um habitus, com o qual seus produtores, como agentes sociais, negociavam acesso ao poder e, eventualmente, a seu ambiente social, político e institucional". ${ }^{108}$ Enfim, há tanto as derivações do uso privilegiado da escrita, quanto o papel da escrita e dos objetos inscritos como meios de estabelecimento e propagação la quem quer que fosse) de uma ideologia sustentadora da realeza.

Dessa maneira, de acordo com Berti et al., a presença da escrita em contextos arquiteturais abre como campo de observação o potencial impacto de sua própria materialidade. A perspectiva desses autores também a considera uma influência mútua entre a presença da escrita num ambiente arquitetônico e o espaço como influenciador de sua percepção. ${ }^{109}$ Tal interação num dado ambiente depende da presença humana como audiência (desejada ou não) e como um agente que percebe de algum modo a escrita num ambiente arquitetônico - e isso em si é um problema de investigação a ser colocado. Algumas consequências dessas considerações prévias são, por exemplo, o lugar da escrita, seus possíveis significados e sua influência, inclusive no movimento corporal dos sujeitos que circulam pelo espaço. ${ }^{110}$

cenário emblemático de interrelação entre texto e imagens está nos palácios assírios, durante seu período tardio lou período neoassírio, sécs. IX a VII AEC). $\bigcirc$ interior desses palácios é repleto de textos e imagens, em seus baixos relevos parietais. Os exemplos mostram placas com relevos esculpidos e textos inscritos, seja sobre a escultura de figuras (Figura 4), seja em uma caixa de texto separada (Figura 5). O contexto é de uma configuração de ambiente produtor de imagens e textos, algumas vezes colocados sobre um mesmo suporte material. Do

\section{Matthews (2013).}

108. Balke e Tsouparopoulou (2016, p. 2).

109. Berti et al. (2017).

110. Em Berti et al. (2017), essa dinâmica é explorada por V. Debiais (2017). 
112. Ranieri (2018, p. 84).

113. Muth et al. (2012, p. 221). Para além de estelas, obeliscos e pedras de fronteira (em acadiano chamadas de kudurru), em que se encontram imagens e inscrições compartilhando o mesmo suporte, outros casos são as estátuas de soberanos com inscrições em partes específicas. Cf. Winter (1989) sobre a estátua de Gudea (soberano da cidade de Lagash, sul da Mesopotâmia, no fim do III milênio AEC) e Crawford (2014), sobre estátua de Idrimi (soberano da cidade de Alalakh no século XV AEC, na atual Síria). ponto de vista metodológico, a natureza dessas fontes estimulou a análise conjunta de fontes materiais e escritas, ${ }^{111}$ a ponto de uma complementaridade servir como categoria de análise. "Desse modo, textos e relevos fazem parte de um ambiente de produção material e textual [centralizada na figura do soberano] onde ambas as naturezas expressivas (materialidade e textualidade) podem confluir-se". ${ }^{112}$ Segundo Muth et al., a presença de imagens e textos num mesmo suporte não é, para a realidade da antiguidade, estabelecida numa hierarquia de elementos expressivos e comunicativos, mas sim configura uma realização concomitante, envolvendo a interação de elementos textuais e iconográficos. ${ }^{113}$

Figura 4 - Placa com escultura em baixo relevo, palácio Noroeste de Nimrud (séc. IX AEC). Na placa, a inscrição em cuneiforme foi feita em sua parte medial, perpassando a figura esculpida. Fonte: (OThe Trustees of the British Museum (BM 124560).

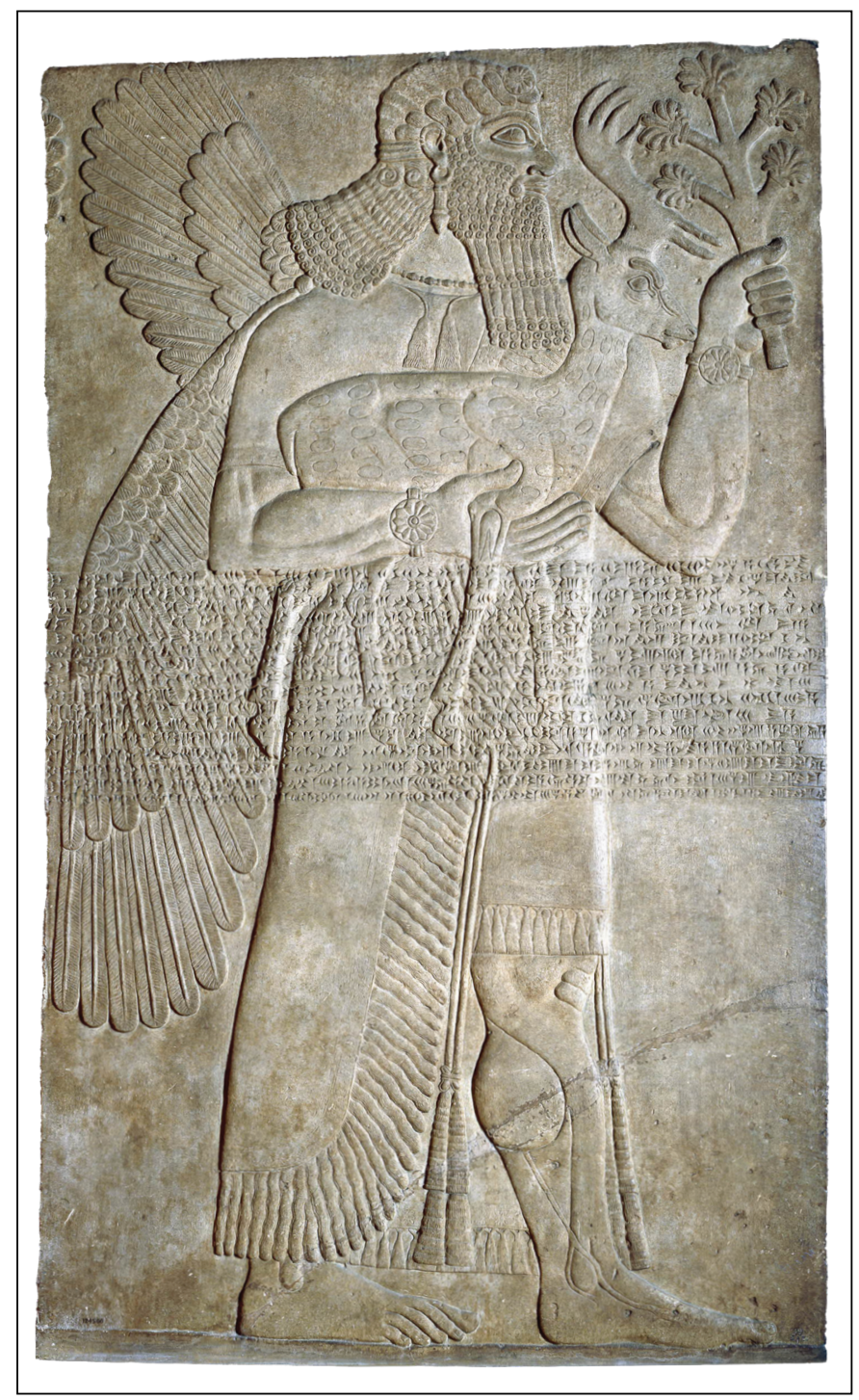




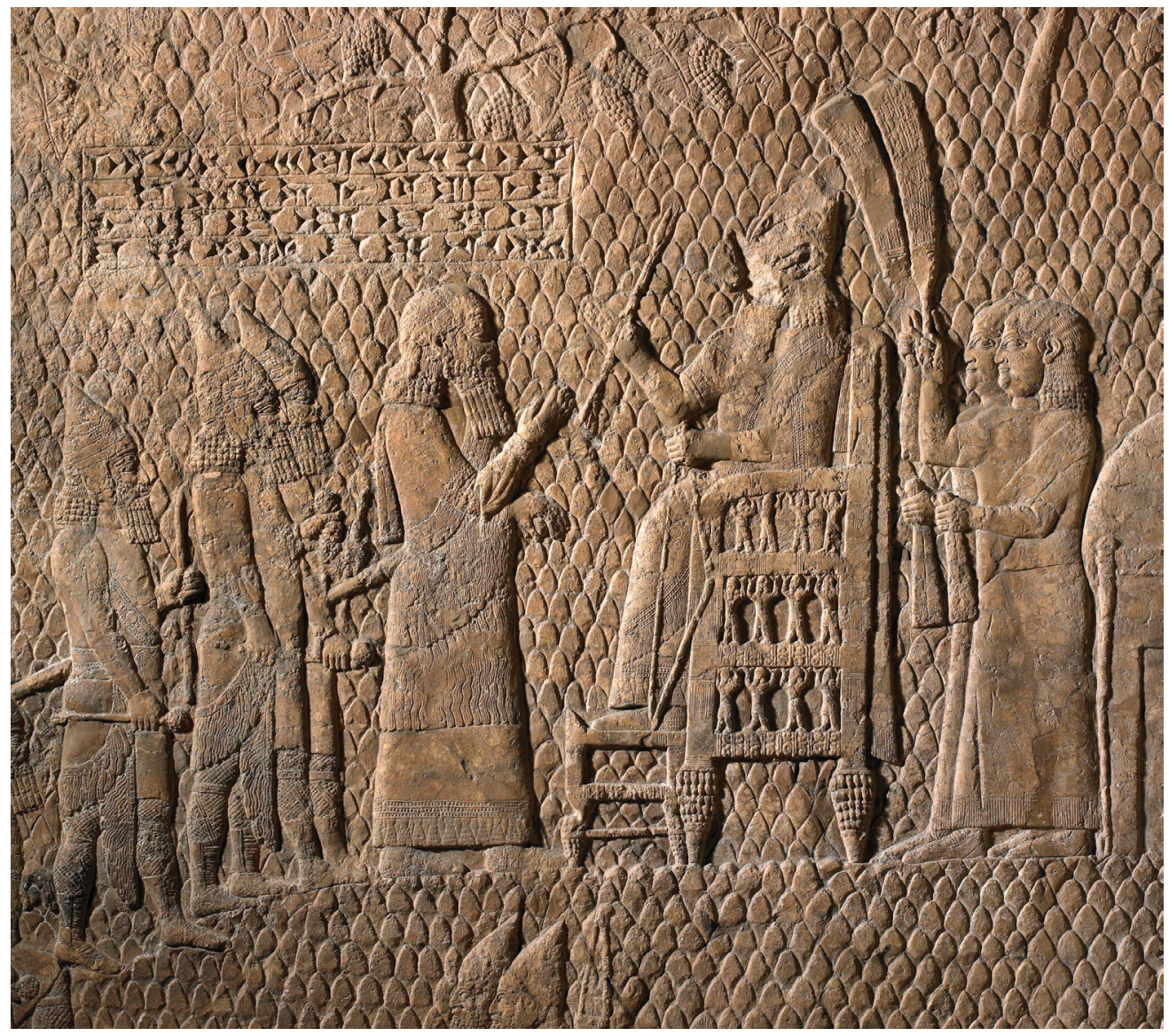

Figura 5 - Recorte e detalhe de placa de pedra esculpida em baixo relevo, do palácio sudoeste de Nínive (Séc. VIII-VII AEC). Na parte centro-superior da imagem, há uma pequena caixa contendo uma inscrição em cuneiforme. Fonte: (OThe Trustees of the British Museum (BM 12491 1).

Considerando a complementaridade entre fontes escritas e de cultura material, tal componente serve para se analisar diferentes aspectos evocados por essas fontes. A configuração arquitetônica - e, portanto, material-da espacialidade palaciana também despertou análises sobre seu programa intencional, a ponto de conduzir a movimentação corporal, visual e cognitiva, bem como despertar um ambiente com estímulos sensoriais intencionados. ${ }^{114}$ Sendo assim, a disposição dos relevos nas paredes dos palácios, que implica uma programação, corresponde ao que está nos relevos (textos e imagens) e à posição do observador para que sejam vistos. Além disso, tal disposição inclui a interação com as próprias pessoas representadas (e, aqui, destaca-se, por exemplo, a figura do rei, especialmente nas salas dos tronos dos palácios), bem como os elementos individuais e os motivos gerais têm em muitas situações posições específicas nas salas. ${ }^{115}$
114. Cf. Portuese (2019) sobre o palácio Noroeste de Nimrud, de Assurnasirpal II (século IX AEC). Após as contribuições de Winter sobre a implicação das imagens no movimento pelo espaço palaciano, avançadas também por Nadali (2006, 2008, 2014), há ganhos a partir de abordagens arqueológicas voltadas à percepção do espaço monumental, com implicações à relação entre sensorialidade e espacialidade. Sobre o potencial da arquitetura monumental para ser entendida como um ambiente sensorial (chamado também, em inglês, de sensescape), Cf. McMahon (2013) Thomason (2016), Neumann (2018).

115. Cf. Winter (2010) e Nadali (2006, 2008, 2014). 
Nesse sentido, a complementaridade entre texto e imagem não ocorre como um preenchimento de lacunas, isto é, de um preenchimento mútuo em que um objeto contém um aspecto que outro não apresenta (e vice-versa). Ao contrário, ao se considerar o espaço, as pessoas e as intenções como elementos de uma rede de interação na qual textos e imagens estão incluídos, a complementaridade das fontes é de tipo funcional: texto e imagem manifestam-se juntos, têm suas funções particulares e que muitas vezes interagem. ${ }^{116}$

\section{CONSIDERAÇÕES FINAIS: MATERIALIDADE DA ESCRITA E DOS TABLETES CUNEIFORMES COMO UM CAMPO DE OBSERVAÇÃO}

Este artigo objetivou compreender a relação entre a materialidade da escrita e a escrita cuneiforme no contexto da antiga Mesopotâmia. Assim como tantos outros objetos inscritos, os tabletes de argila são prioritariamente tratados como suportes que recebem e transportam a escrita cuneiforme. Partindo da discussão de como as abordagens tradicionais - sobretudo o modelo linguístico aplicado às pesquisas arqueológicas e historiográficas - levaram à desmaterialização da escrita, buscamos apresentar possibilidades de retorno à sua materialidade. Assim, ao considerar a materialidade da escrita como parte integrante da dinâmica social, novos olhares podem ser lançados sobre o papel dos tabletes cuneiformes dentro de seus contextos específicos de produção e uso/circulação.

Ao retomarmos o contexto de produção dos tabletes de argila, ou ao imaginarmos uma pessoa em vias de escrever ou preparar seu suporte de escrita, nos deparamos com uma agência dos objetos que funciona em meio a agência de sujeitos, ou no espaço entre ambos. $\bigcirc$ que flui nesse espaço são objetos previamente modelados a partir de elementos essenciais, como a terra e a água. Essa materialidade toma formas diversas, dependendo da informação e do conteúdo a ser gravado. Por sua vez, a produção dos tabletes implica o cuidado para sua finalização, transporte e armazenamento. Nessas etapas, há espacialidades diferentes, tanto de onde se tira e se prepara a matéria prima, como para onde se carregam e se armazenam os tabletes. Uma espacialidade intermediária também se desenrola entre esses processos, que inclui o sujeito que escreve no tablete, a finalização da escrita e os processos posteriores de sua produção, como sua releitura após armazenamento.

momento da escrita propriamente poderia se dar numa faixa temporal bastante variável, da iminência do ato de escrever tendo diante de si o suporte ou até o preparo parcial do material para sua complementação a posteriori. Aliás, a temporalidade dessa materialidade se estende, por exemplo, em seu armazenamento 
duradouro, sua destruição e transformação em outros tabletes, a consulta dos materiais prontos pelos estudantes das escolas de escribas e de textos modelares 118. Basu (2017, p. 14). e canônicos e a preservação memorial (em templos, palácios e monumentos). Em todos os espaços, observamos agentes humanos e materiais implicados, individualmente ou em interação, com gestos e ações específicos.

Da argila ao texto escrito, o tablete se faz, faz o escriba, que também faz o tablete. A vida do tablete é uma etapa da vida da argila, e esta é uma etapa da vida do texto. Elas emergem e se dão numa zona de interrelações em fluxo constante, num interstício, onde se encontram, do modo que diferenciamos sujeitos, objetos e seu meio. Todos eles acontecem e se fazem nesse acontecer junto. E essa é a perspectiva de Ingold, ${ }^{117}$ explorada neste artigo problematizando a materialidade da escrita cuneiforme.

A materialidade da escrita dos tabletes de argila é uma secção do fluxo contínuo de correspondências entre sujeitos, meios e objetos. Ao entendermos historicamente aspectos desse momento - ou, nos termos de Basu, ${ }^{118}$ da cristalização do processo de fluxo - os interstícios das relações emergem. No entanto, uma descrição esquemática não deveria servir como ponto de partida e retorno para se compreender a materialidade da escrita cuneiforme somente a partir do esquema linguístico, mas sim como um processo de correspondência: texto e matéria respondem e são responsivos, transformam e são transformados no contínuo de relações.

Todos esses elementos descritos, bem como os estudos de caso levantados aqui, podem ser tomados como campos ou recortes de observação e análise. Tudo isso depende da documentação disponível, inclusive dos dados arqueológicos essenciais ao conhecimento do contexto, bem como dos aspectos de forma/ formato. ${ }^{119}$ Também depende de outras concepções relacionadas ao seu contexto de produção, ou melhor, ao conjunto de atividades de percepção e decisão que se dá no engajamento da vida. ${ }^{120}$ 


\section{REFERÊNCIAS}

LIVROS, ARTIGOS E TESES

ALMADA, Márcia. Introdução: considerações sobre a materialidade da escrita e as três camadas de informação. Anais do Museu Paulista, São Paulo, v. 28, p. 1-13, 2020. Doi: <https://www. doi.org/10.1590/1982-02672020v28d3e42intro2>.

BACHELOT, Luc. Corps, image et perception de l'espace: l'apport de la phénoménologie. In: GILLMANN, Nicolas; SHAFER, Ann (eds.). Corps, image et perception de l'espace: de la Mésopotamie au monde classique. Paris: L'Harmattan, 2014. p. 13-32.

BALKE, Thomas; TSOUPAROPOULOU, Christina. Introduction. In: Materiality of writing in Early Mesopotamia. Berlin: De Gruyter, 2016. p. 1-10. Doi: <https://www.doi. org/10.1515/9783110459630-001>.

BALKE, Thomas et al. Ton. In: MEIER, Thomas et al. (eds.). Materiale Textkulturen: Konzepte - Materialien - Praktiken. Berlin: De Gruyter, 2015. p. 277-292. Doi: <https://www.doi. org/10.1515/9783110371291.277>.

BASU, Paul. The inbetweenness of things. In: The inbetweenness of things: materializing mediation and movement between worlds. London: Bloomsbury, 2017. p. 1-20.

BERTI, Irene et al. Introduction. In: Writing matters: presenting and perceiving monumental inscriptions in Antiquity and the Middle Ages. Berlin: De Gruyter, 2017. p. 1-12. Doi: <https:// www.doi.org/10.1515/9783110534597-001>.

BOIVIN, Nicole. Grasping the elusive and unknowable: material culture in ritual practice. Material Religion, London, v. 5, n. 3, p. 266-287, 2009. Doi: <https://www.doi.org/10.2752/1 75183409X12550007729860>.

BOURDIEU, Pierre. Raisons pratiques: sur la théorie de l'action. Paris: Editions du Seuil, 1994.

BRAMANTI, Armando. Dall'Antico Oriente alle nostre mani: la materialità del cuneiforme. Forma Urbis, Roma, v. 33, n. 10, p. 27-32, 2018. Disponível em: <https://bit.ly/3Deo1Lt>. Acesso em: 23 ago. 2021.

BRAMANTI, Armando. The cuneiform stylus: some addenda. Cuneiform Digital Library Notes, Los Angeles, n. 12, 2015. Disponível em: <https://bit.ly/3j7EFVg>. Acesso em: 23 ago. 2021.

BROOKES, Sophia. A new approach to the design of kiln furniture for the firing of cuneiform tablets. Iraq, London, v. 59, p. 203-207, 1997. Doi: <https://www.doi.org/10.2307/4200444>. 
CAMmAROSANO, Michele. The cuneiform stylus. Mesopotamia: Rivista di Archeologia, Epigrafia e Storia Orientale Antica, Firenze, v. 49, p. 53-90, 2014.

CARDOSO, Ciro Flamarion. História e textualidade. In: CARDOSO, Ciro Flamarion; VAINFAS, Ronaldo (orgs.). Novos domínios da história. Rio de Janeiro: Elsevier, 2012. p. 225-241.

CHARPIN, Dominique. Lire et écrire à Babylone. Paris: PUF, 2008.

CHARPIN, Dominique. Writing, law and kingship in Old Babylonian Mesopotamia. Chicago: University of Chicago Press, 2010.

COHEN, Sol. Enmerkar and the Lord of Aratta. 1973. Tese (Doutorado) - Faculty of the Graduate School of Arts and Sciences, University of Pennsylvania, Philadelphia, 1973.

CRAWFORD, Cory D. Relating image and word in Ancient Mesopotamia. In: BROWN, Brian A.; FELDMAN, Marian H. (eds.). Critical approaches to Ancient Near Eastern art. Berlin: De Gruyter, 2014, p. 241-264. Doi: <https://www.doi.org/10.1515/9781614510352.241>.

DEBIAIS, Vincent. Writing on medieval doors: the Surveyor Angel on the Moissac Capital (ca. 1100). In: BERTI, Irene et al. (eds.). Writing matters: presenting and perceiving monumental inscriptions in Antiquity and the Middle Ages. Berlin: De Gruyter, 2017. p. 285-308. Doi: <https://www.doi.org/10.1515/9783110534597-012>.

DELNERO, Paul; LAUINGER, Jacob. Introduction: reassembling the social from text and contexts. In: DELNERO, Paul; LAUINGER, Jacob (eds.). Texts and contexts: the circulation and the transmission of cuneiform texts in social space. Berlin: De Gruyter, 2015. p. 1-26. Doi: <https://www.doi.org/10.1515/9781614515371-001>.

FAIVRE, Xavier. Le recyclage des tablettes cuneiformes. Revue d'Assyriologie et d'archéologie orientale, Paris, v. 89, n. 1, p. 57-66, 1995.

FATTORI, Anita. 50 cartas de Tell Harmal: práticas administrativas e sociabilidade no antigo reino de Eshnunna. 2018. Dissertação (Mestrado em Filosofia) - Escola de Artes, Ciências e Humanidades, Universidade de São Paulo, São Paulo, 2019. Doi: <https://www.doi. org/10.11606/D.100.2019.tde-03022019-183741>.

FINLEY, Moses Israel. Grécia primitiva: Idade do Bronze e Idade Arcaica. São Paulo: Martins Fontes, 1990.

GELL, Alfred. Art and agency: an anthropological theory. Oxford: Clarendon, 1998.

GEORGE, Andrew. Appendix: from tablet to translation. In: GEORGE, Andrew. The epic of Gilgamesh. London: Penguin, 1999. p. 209-221.

GIBSON, James. The ecological approach to visual perception. Boston: Houghton-Mifflin, 1979. 
GIDDENS, Anthony. The constitution of society: outline of the theory of structuration. Berkeley: University of California Press, 1984.

GLASSNER, Jean-Jacques. Écrire à Sumer: l'invention du cunéiforme. Paris: Éditions du Seuil, 2000.

GÖTZE, Albrecht. Fifty old Babylonian letters from Harmal. Sumer, [s. l.], n. 14, p. 3-79, 1958.

HICKS, Dan. The material-cultural turn: event and effect. In: HICKS, Dan; BEAUDRY, Mary (eds.). The Oxford handbook of material culture studies. Oxford: Oxford University Press, 2010. p. 25-98.

HODDER, Ian. This is not an article about material culture as text. Journal of Anthropological Archaeology, Amsterdam, v. 8, n. 3, p. 250-269, 1989. Doi: <https://www.doi.org/10.1016/02784165(89)90015-9>.

HODDER, Ian; HUTSON, Scott. Reading the past: current approaches to interpretation in archaeology. Cambridge: Cambridge University Press, 2003.

HUSSEIN, Laith. Tell Harmal: Die Texte aus dem Hauptverwaltungsgebäude 'Serai'. 2006. Tese (Doutorado) - Philipps-Universität Marburg, Marburg, 2009.

INGOLD, Tim. Bringing things back to life: creative entanglements in a world of materials. Manchester: Realities, University of Manchester, 2010. Disponível em: <https://bit.ly/3gKJq5F>. Acesso em: 3 jul. 2020.

INGOLD, Tim. Culture and the perception of the environment. In: CROLL, Elisabeth; PARKIN, David (eds.). Bush base: forest farm: culture, environment and development. London: Routledge, 1992. p. 39-56.

INGOLD, Tim. Materials against materiality. Archaeological Dialogues, Cambridge, v. 14, n. 1, p. 1-16, 2007. Doi: <https://www.doi.org/10.1017/S1380203807002127>.

INGOLD, Tim. The life of lines. London: Routledge, 2015.

INGOLD, Tim. The perception of the environment: essays on livelihood, dwelling and skill. London: Routledge, 2000.

KARAGIANNI, Angeliki; SCHWINDT, Jürgen P.; TSOUPAROPOULOU, Christina. Materialität. In: MEIER, Thomas; OTT, Michel R.; SAUER, Rebecca (eds.). Materiale Textkulturen: Konzepte - Materialien - Praktiken. Berlin: De Gruyter, 2015. p. 33-46. Doi: <https://www.doi. org/10.1515/9783110371291.33>.

KNAPPETT, Carl. Materiality in archaeological theory. In: SMITH, Claire (ed.). Encyclopedia of global archaeology. New York: Springer, 2014. p. 4700-4708. Doi: <https://www.doi. org/10.1007/978-1-4419-0465-2_292>. 
KNAPPETT, Carl. Materiality. In: HODDER, Ian (ed.). Archaeological theory today. Cambridge: Polity, 2012. p. 188-207.

KNAPPETT, Carl. Materials with materiality? Archaeological Dialogues, Cambridge, n. 14, v. 1, p. 20-23, 2007. Doi: <https://www.doi.org/10.1017/S1380203807002140>.

KRAMER, Samuel Noah. Enmerkar and the Lord of Aratta: a Sumerian epic tale of Iraq and Iran. Philadelphia: University of Pennsylvania Press, 1952.

LATOUR, Bruno. Pandora's hope: essays on the reality of science studies. Cambridge: Harvard University Press, 1999.

LATOUR, Bruno. Reassembling the social: an introduction to Actor-Network Theory. Oxford: Oxford University Press, 2005.

LAW, John. Notes on the theory of the actor-network: ordering, strategy and heterogeneity. Systems Practice, [s. l.], v. 5, p. 379-393, 1992. Doi: <https://www.doi.org/10.1007/BF01059830>.

MALAFOURIS, Lambros. How things shape the mind: a theory of material engagement. Cambridge: The MIT Press, 2013.

MATTHEWS, Roger. Writing (and reading) as material practice: the world of cuneiform culture as an arena for investigation. In: PIQUETTE, Kathryn; WHITEHOUSE, Ruth (eds.). Writing as material practice: substance, surface and medium. London: Ubiquity Press, 2013. p. 65-74. Doi: <https://www.doi.org/10.5334/bai.d>.

MCMAHON, Augusta. Space, sound, and light: toward a sensory experience of ancient monumental architecture. American Journal of Archaeology, Boston, v. 117, n. 2, p. 163, 2013. Doi: <https://www.doi.org/10.3764/aja.117.2.0163>.

MENESES, Ulpiano Toledo Bezerra de. História e imagem: iconografia/iconologia e além. In: CARDOSO, Ciro Flamarion; VAINFAS, Ronaldo (orgs.). Novos domínios da bistória. Rio de Janeiro: Elsevier, 2012. p. 243-262.

MESKELL, Lynn. Introduction: object orientations. In: MESKELL, Lynn (ed.). Archaeologies of Materiality. Oxford: Blackwell, 2005. p. 1-17. Disponível em: $<$ https://bit.ly/3gpNnfE $>$. Acesso em: 23 ago. 2021.

MUTH, Susanne et al. Texte et image dans l'Antiquité: lire, voir et percevoir. Perspective, [s. l.], v. 2, p. 219-236, 2012. Doi: <https://www.doi.org/10.4000/perspective.145>.

NADALI, Davide. Moveo, ergo sum: living in the space around us: distance, perspective and reciprocity. In: GILLMANN, Nicolas; SHAFER, Ann (eds.). Corps, image et perception de l'espace: de la Mésopotamie au Monde Classique. Paris: L’Harmattan, 2014. p. 33-55. 
NADALI, Davide. Percezione dello spazio e scansione del tempo: studio della composizione narrativa del rilievo assiro di VII secolo a.C. Roma: Università degli studi di Roma La Sapienza, 2006.

NADALI, Davide. The role of the image of the king in the organizational and compositional principles of Sennacherib's throne room: a guide to the historical narrative and meaning of a specified message. In: KÜHNE, Hartmut; CZICHON, Rainer Maria; KREPPNER, Florian Janoscha (eds.). Proceedings of the 4 th International Congress of the Archeology of the Ancient Near East. Wiesbaden: Harrassowitz Verlag, 2008. v. 1, p. 473-493.

NEUMANN, Kiersten. Reading the Temple of Nabu as a coded sensory experience. Iraq, London, v. 80, p. 181-211, 2018. Doi: <https://www.doi.org/10.1017/irq.2018.11>.

ORGAN, Robert. The conservation of cuneiform tablets. The British Museum Quarterly, v. 23, n. 2 , p. 52-58, 1961.

PARPOLA, Simo. Letters from Assyrian and Babylonian Scholars. Winona Lake: Eisenbrauns, 2014.

PEARCE, Laurie. Materials of writing and materiality of knowledge. In: STACKERT, Jeffrey; PORTER, Barbara Nevling; WRIGHT, David (eds.). Gazing on the deep: Ancient Near Eastern and other studies in honor of Tzvi Abusch. Bethesda: CDL, 2010. p. 167-79.

PESEZ, Jean-Marie. História da cultura material. In: LE GOFF, Jacques (org.). A bistória nova. São Paulo: Martins Fontes, 1993. p. 177-213.

PIQUETTE, Kathryn; WHITEHOUSE, Ruth. Introduction: developing an approach to writing as material practice. In: Writing as material practice: substance, surface and medium. London: Ubiquity, 2013. p. 1-13. Disponível em: <https://bit.ly/3khRlIx>. Acesso em: 24 ago. 2021.

PORTUESE, Ludovico. The Throne Room of Aššurnasirpal: a multisensory experience. In: HAWTHORN, Ainsley; LOISEL, Anne-Caroline Rendu (eds.). Distant impressions: the senses in the Ancient Near East. Pennsylvania: Eisenbrauns, 2019. p. 63-92.

RADNER, Karen. The relation between format and content of Neo-Assyrian texts. In: MATTILA, Raija. Nineveh, 612 BC: the glory and fall of the Assyrian Empire. Helsinki: Helsinki University Press, 1995. p. 63-77.

RANIERI, Leandro Penna. Concepções de corpo na Assíria do primeiro milênio AEC: entre materialidade e textualidade. 2018. Tese (Doutorado em História Social) - Faculdade de Filosofia, Letras e Ciências Humanas, Universidade de São Paulo, São Paulo, 2018. Doi: <https:// www.doi.org/10.11606/T.8.2018.tde-23112018-123812>.

REDE, Marcelo. Complexidade social, sistemas comunicativos e gênese da escrita cuneiforme. Classica, Belo Horizonte, v. 11-12, n. 11-12, p. 37-53, 1998-1999. Doi: <https://www.doi. org/10.24277/classica.v11i11/12.448>. 
REDE, Marcelo. História e cultura material. In: CARDOSO, Ciro Flamarion; VAINFAS, Ronaldo (orgs.). Novos domínios da história. Rio de Janeiro: Elsevier-Campus, 2012. p. 133-150.

RENFREW, Colin. Towards a cognitive archaeology. In: RENFREW, Colin; ZUBROW, Ezra (eds.). The ancient mind: elements of cognitive archaeology. Cambridge: Cambridge University Press, 1994. p. 3-12.

RENFREW, Colin. Towards a theory of material engagement. In: DEMARRAIS, Elizabeth; GOSDEN, Chris; RENFREW, Colin (eds.). Rethinking materiality: the engagement of mind with the material world. Cambridge: McDonald Institute for Archaeological Research, 2004. p. 23-32.

RENFREW, Colin. Towards an archaeology of mind: an inaugural lecture delivered before the University of Cambridge on 30 November 1982. Cambridge: Cambridge University Press, 1982. p. 1-34.

STEADMAN, Sharon; ROSS, Jennifer. Agency and identity in the Ancient Near East. In: STEADMAN, Sharon; ROSS, Jennifer (eds.). Agency and identity in the Ancient Near East: new paths forward. London: Equinox, 2010. p. 1-10.

TAYLOR, Jonathan. Tablets as artefacts, scribes as artisans. In: RADNER, Karen; ROBSON, Eleanor (eds.). The Oxford Handbook of cuneiform culture. Oxford: Oxford University Press, 2011. p. 5-31.

TAYLOR, Jonathan; CARTWRIGHT, Caroline. The making and re-making of clay tablets. Scienze dell'Antichità, Roma, v. 17, p. 297-324, 2011. Disponível em: <https://bit.ly/3kmFWXW>. Acesso em: 24 ago. 2021.

TEIXEIRA-BASTOS, Márcio; FERREIRA, Lucio Menezes; HODDER, Ian. Isso não é um artigo: dialogando com Ian Hodder sobre a virada ontológica em arqueologia. Revista de Arqueologia, Teresina, v. 33, n. 2, p. 118-134, 2020. Doi: <https://www.doi.org/10.24885/sab.v33i2.775>.

THOMASON, Allison. The sense-scapes of Neo-Assyrian capital cities: royal authority and bodily experience. Cambridge Archaeological Journal, Cambridge, v. 26, n. 2, p. 243-264, 2016. Doi: <https://www.doi.org/10.1017/S0959774315000578>.

TILLEY, Christopher. Interpreting material culture. In: HODDER, Ian (ed.). The meaning of things: material culture and symbolic expression. London: Unwin Hyman, 1989. p. 185-194.

TILLEY, Christopher. Materiality in materials. Archaeological Dialogues, Cambridge, v. 14, n. 1, p. 16-20, 2007. Doi: <https://www.doi.org/10.1017/S1380203807002139>.

TINNEY, Steve. Texts, tablets, and teaching: scribal education in Nippur and Ur. Expedition, Philadelphia, v. 40, n. 2, p. 40-50, 1998. Disponível em: <https://bit.ly/3ze8lp3>. Acesso em: 24 ago. 2021. 
TSOUPAROPOULOU, Christina. Deconstructing textuality, reconstructing materiality. In: BALKE, Thomas; TSOUPAROPOULOU, Christina (eds.). Materiality of writing in Early Mesopotamia. Berlin: De Gruyter, 2016. p. 257-276. Doi: <https://www.doi.org/10.1515/9783110459630-012>.

TRENTMANN, Frank. Materiality in the future of history: things, practices, and politics. Journal of British Studies, Cambridge, v. 48, n. 2, p. 283-307, 2009. Doi: <https://www.doi. org/10.1086/596123>.

VANSTIPHOUT, Herman. Epics of Sumerian kings: the matter of Aratta. Atlanta: Society of Biblical Literature, 2003.

VANSTIPHOUT, Herman. Memory and literacy in the Ancient Western Asia. In: SASSON, Jack (ed.). Civilizations of the Ancient Near East. New York: Charles Scribner's Sons, 1995. v. 4, p. 2181-2196.

VELDHUIS, Niek. Levels of literacy. In: RADNER, Karen; ROBSON, Eleanor (eds.). The Oxford Handbook of cuneiform culture. Oxford: Oxford University Press, 2011. p. 205-224.

VERDERAME, Lorenzo. Letterature dell'antica Mesopotamia. Milano: Mondadori, 2016.

VERDERAME, Lorenzo. Text, context, and the social dimension of the writing: a case study from the Early Dynastic Inanna Temple at Nippur. In: EVANS, Jean M.; ROBERGER, Elisa (eds.). Ancient Near Eastern temple inventories in the Third and Second Millennia BCE: integrating archaeological, textual, and visual sources. Gladbeck: PeWe-Verlag, 2019. p. 27-44.

VON DASSOW, Eva. Figure and ground: reading Ancient Near East sources. In: SIMPSON, Elizabeth (ed.). The adventure of the illustrious scholar: papers presented to Oscar White Muscarella. Leiden: Brill, 2018. p. 818-838.

WINTER, Irene. Art in empire: the royal image and the visual dimensions of Assyrian ideology. In: WINTER, Irene (ed.). On art in the Ancient Near East. Leiden: Brill, 2010. v. 1, p. 71-108. Doi: <https://www.doi.org/10.1163/ej.9789004172371.i-640.14>.

WINTER, Irene. The body of the able ruler: toward an understanding of the statues of Gudea. In: BEHRENS, Hermann et al. (eds.). Dumu-É-dub-ba-a: studies in honor of A. W. Sjöberg. Philadelphia: The University Museum, 1989. p. 573-583.

Artigo apresentado em: 22/12/2020. Aprovado em: 16/04/2021. (c) BY 